Est Ag 47 (2012) 449-492

\title{
El impuesto al César (Mc 12,13-17) y la labor redaccional del evangelista
}

\author{
David Álvarez Cineira ${ }^{1}$
}

SUMARIO: La anexión de Judea al Imperio supuso el pago del impuesto de capitación, cuya exacción era realizada por la administración religiosa judía. No estaba estipulado que su contribución se efectuara en metálico, pudiéndose realizar con monedas de bronce, monedas de Tiro o, incluso, mediante productos agrícolas (grano...). Además, los estudios numismáticos han corroborado que la monetización romana de denarios era escasa en Judea para esta época, lo cual haría inviable que los judíos pudieran abonar el impuesto en denarios imperiales. La mención del "denario" y de los "herodianos" en el relato de Mc 12,13-17 se debe a la labor editorial del evangelista o de la comunidad de Roma, quien reelabora un logion de Jesús para afrontar una imposición: la tributación del fiscus Iudaicus en la capital del imperio.

PALABRAS CLAVE: Impuestos, denario, herodianos, labor redaccional de Mc

ABSTRACT: The annexation of Judea to the Empire assumed the payment of poll tax, which was levied by the Jewish religious administration. It was not stipulated that the payment will be made in cash, and it could be be done with bronze coins, coins of Tyre or even grain. In addition, numismatic studies have confirmed that the monetization of Roman denarii was scarce in Judea at that time, which would make it impossible for the Jews to pay it with imperial denarii. The mention of the "denarius" and the "Herodians" in Mark 12:13-17 is due to the editorial work of the evangelist, who reelaborated a logion of Jesus to face a conflict in his Roman community: the taxation of the fiscus Iudaicus.

\footnotetext{
${ }^{1}$ Correo electrónico: dacineira@hotmail.com
} 
KEY WORDS: Taxes in Palestine, denarius, Herodians, Markan redactional work

El imperio romano constituyó el contexto histórico, religioso y cultural en que Jesús vivió, aunque su actividad se desarrolló en un área rural insignificante y alejada del poder imperial. Más imbuidos de esa cultura se encontraban los autores y destinatarios de los evangelios escritos en griego, que presuponen un Sitz im Leben urbano donde la presencia romana era mucho más patente que en Galilea. Es lógico, por tanto, que se intente descubrir la actitud de Jesús frente al imperio dentro de estos evangelios, tema al que se han dedicado diversas monografías en los últimos decenios. Si Jesús proclamó la inminente llegada del reino de Dios, ese mensaje contenía implicaciones sociales y un desafío político para quienes detentaban el poder. Según el parecer de varios autores, el mensaje del reino de Dios significaba el rechazo del imperio romano, ya que no era el emperador, sino Dios quien regía los destinos del mundo². Además, Jesús jugaba un papel relevante en la llegada de ese reino, e incluso realizó actos provocadores que desafiaban el status quo (p.e. una pretendida entrada triunfal en Jerusalén), actitud y mensaje que fueron castigados con la condena a muerte.

Al margen de este y otros pasajes que pudieran considerarse desafiantes para las autoridades romanas, la perícopa del pago de los impuestos (Mc 12,13-18; Lc 20,20-26; Mt 22,15-22) trasmite uno de los textos más claros del NT, donde Jesús viene interrogado de forma directa sobre una comprometida cuestión política, ya que es confrontado con un aspecto esencial de la dominación romana: el pago de los impuestos al imperio. "Nos encontramos aquí ante una de las preguntas más tensas de todo el evangelio"3. Sus interlocutores esperan una respuesta incriminatoria: una contestación negativa o afirmativa habría causado igualmente problemas a Jesús, bien teológicos o políticos, pues aparecería como un revolucionario contra Roma o un colaboracionista del imperio. Es significativa, sin embargo, la ausencia de dichos de Jesús que ataquen directamente el sistema fiscal de

2 Cf. las publicaciones de John Dominic Crossan, God \& Empire, Jesus against Rome, then and now, HarperSanFrancisco, New York 2007, 97-142; Richard A. Horsley, Hearing the Whole Story. The Politic of Plot in Mark's Gospel, Westminster John Knox Press, Louisville - London - Leiden 2001. En contra, cf. Christopher Bryan, Render to Caesar. Jesus, the Early Church, and the Roman Superpower, University Press, Oxford 2005, 42: "Jesus stood foursquare with the biblical and prophetic attitudes toward political and imperial power represented by Nathan, Jeremiah, Daniel, and Deutero-Isaiah: he would acknowledge such power, but he would also (and therefore) hold it accountable".

3 J. Gnilka, El evangelio según San Marcos. Vol. II: Mc 8,27-16,20 (BEB 56), Sígueme, Salamanca 1986, 178. 
impuestos e, incluso, en su relación con Zaqueo, jefe de los püblicanos, no aboga por una transformación del sistema fiscal (Lc 3,13).

La perícopa ha llamado la atención de los estudiosos desde hace décadas $^{4}$ y ha planteado infinidad de problemas a nivel del relato y de su historicidad, discutiéndose si la respuesta de Jesús se refiere al pago del tributo o más bien encontramos aquí una confrontación con la ideología del culto al emperador representada por la imagen e inscripción de la moneda ${ }^{5}$. En el presente artículo abordaré la temática del sistema tributario romano dentro de Palestina en tiempos de Jesús. Ello nos permitirá dilucidar ¿a qué tipo de impuesto se están refiriendo los interlocutores de Jesús según el relato marcano? En estrecha relación con la tipología de gravámenes fiscales se encuentra el sistema de recaudación y las formas de pago. Por su parte, las formas de tributación nos llevarán a cuestionar si la moneda habitual para tributar era el denario romano o existía algún otro tipo de moneda con la que efectuar el pago. Además, la aversión de los piadosos judíos de Palestina hacia las imágenes cargadas de toda una simbología cultual pagana (p.e. culto al emperador), como eran las monedas romanas del emperador, hace improbable que le mostraran a Jesús un denario imperial en el Templo. Por consiguiente, es probable que la inclusión del denario fuera un añadido redaccional del evangelista o del último redactor en aras de su audiencia romana.

Si esa conclusión se mostrara correcta, tendríamos que plantear la posible existencia de otro contexto vital verosímil en la comunidad de $\mathrm{Mc}$ para el debate acerca del tributo y la respuesta de Jesús ${ }^{6}$. En otro próximo artículo, íntimamente conexo con el presente, expondré que la mano redaccional de Mc no se circunscribió únicamente a la moneda sino también a los interlocutores (Mc 12,13), identificando a los herodianos con los res-

${ }^{4}$ Ethelbert Stauffer, Christus und die Caesaren. Historische Skizzen, Friederich Wittig Verlag, Hamburg 1948, 118-149; Werner Stenger, "Gebt dem Kaiser, was des Kaisers ist...!" Eine sozialgeschichliche Untersuchung zur Besteuerung Palästinas in neutestamentlicher Zeit (Theologie BBB 68), Athenäum, Frankfurt am Main 1988; Fabian E. Udoh, To Caesar What Is Caesar's: Tribute, Taxes, and Imperial Administration in Early Roman Palestine (Brown Judaic Studies 343), Brown University, Providence, RI, 2006. Rafael Aguirre Monasterio, El evangelio de Jesucristo y el imperio Romano, en: Estudios Eclesiásticos 86 (2011) 213-240, aquí 223-225.

5 Martin Rist, Caesar or God (Mark 12:13-17)? A Study in "Formgeschichte", en: The Journal of Religion 16 (1936) 317-331, aquí 317ss.

6 M. Eugene Boring, Mark. A Commentary, Westminster John Knox Press, Louisville - London 2006, 335, considera la historia importante para intentar buscar argumentos y arrestar a Jesús. Pero también era importante para Marcos, pues se trataba de un tema actual de su tiempo, en el que la relación de los cristianos ante las exigencias de los gobernadores romanos constituía un problema concreto. 
ponsables de la sinagoga romana de los Herodianos, encargados, probablemente, de la confección del censo tributario del fiscus judaicus e, incluso, de su recaudación de los bolsillos de algunos miembros de la comunidad cristiana en Roma. Ésta se planteaba el interrogante: “¿pagamos o no pagamos" el impuesto dirigido contra los judíos tras la destrucción del Templo? (Mc 12,17). El evangelista/redactor, por tanto, responde a una cuestión acuciante de la comunidad mediante un logion de Jesús, que en su día fue proferido en un contexto distinto al que presenta Mc.

Con esta propuesta creemos responder de forma plausible al interés mostrado por Joel Marcus ${ }^{7}$ por descubrir el contexto vital de esta perícopa en la vida de la comunidad del evangelista. Así, la cuestión del tributo no constituía un mero interés de anticuario para la comunidad de Marcos, sino una cuestión de vida o muerte. Además, la parábola previa de los labradores homicidas (12,1-12) despertaría ecos en el auditorio marcano de la trágica revuelta judía contra los romanos, pero más aún si leían o escuchaban el discurso escatológico de Mc 13,7-23. Este exegeta, por su parte, sitúa la comunidad de Marcos en los albores de la guerra judía contra los romanos, una revuelta desencadenada, entre otros motivos, por la cuestión del pago de los impuestos, por lo que es posible que algunos cristianos conocidos o de esa comunidad, se hayan dejado llevar del entusiasmo revolucionario y se negaran a pagar el impuesto. Considero, sin embargo, que el rechazo a pagar el tributo fue una tentación real para la audiencia de Mc, pero no en Galilea, sino en Roma después de la destrucción del templo, con las consiguientes consecuencias: "Os entregarán a los tribunales, seréis azotados en las sinagogas y compareceréis ante gobernadores y reyes por mi causa para dar testimonio ante ellos" (Mc 13,9).

\section{Los impuestos romanos en Judea en tiempos de Jesús 8}

El desconocimiento del sistema fiscal romano en Palestina puede hacernos pensar que la imagen del relato evangélico es histórica para el

7 Joel Marcus, Mark 8-16 (The Anchor Yale Bible 27A), Yale University Press, New Haven - London 2009, 826 .

8 Jack Pastor, Land and Economy in Ancient Palestine, Routledge, London 1997; Ze'ev Safrai, The economy of Roman Palestine, Routledge, London 1994; Gildas Hamel, Poverty and Charity in Roman Palestine, University of California Press, Berkeley - Los Angeles 1990, 129-148. Para un breve y preciso estudio cf. E. Gabba, The social, economic and political history of Palestine 63 BCE-CE 70, en: William Horbury - W. D. Davies -John Sturdy, The Cambridge History of Judaism. Vol. III: The Early Roman Period, Cambridge University Press, Cambridge 2008, 94-167. Philip A. Harland, The Economy of 
tiempo de Jesús en Jerusalén. Por eso considero importante abordar la cuestión de los impuestos en Judea dentro del contexto de la política romana.

Herederos de la ideología de las ciudades-estado griegas, el gobierno romano no impuso a sus ciudadanos, independientemente de su lugar de residencia, la tasación directa regular sobre las personas ni sobre las tierras poseedoras del ius Quiritium, es decir, Italia, ni sobre los territorios romanos de las colonias y de las ciudades provinciales que poseían el ius Italicum $^{9}$. Por el contrario, los pueblos conquistados contribuían al imperio con sus tributos (de ahí el origen etimológico de tributum -relacionado con el botín de guerra o de conquista- cf. Mt 17,24-27). Al parecer no existió una legislación fiscal uniforme durante la República ni a inicios del Principado debido a que, en general, Roma asumió los regímenes fiscales existentes en los territorios conquistados, adaptándolos a sus propias necesidades y circunstancias específicas. El resultado fue que las diferentes provincias, ciudades-estado y grupos étnicos desarrollaron una amplia variedad de obligaciones fiscales y exenciones frente a la potencia dominadora. Esto mismo sucedió con los judíos, quienes fueron sometidos a diferentes políticas fiscales dependiendo de la época, el lugar y el tipo de relaciones mantenidas con Roma.

Durante el Principado se aplicaron diferentes gravámenes fiscales a las provincias. En primer lugar, cabe mencionar el impuesto directo regular, tributum (en griego se empleaban los vocablos фópo $\varsigma^{10}$ o el latinismo sinónimo $\left.\kappa \hat{\eta} \nu \sigma o \varsigma^{11}\right)$. Este tipo de carga fiscal se subdividía a su vez en tribu-

First-Century Palestine: State of the Scholarly Discussion, en: Anthony J. Blasi - Jean Duhaime - Paul-Andre Turcotte (eds.), Handbook of Early Christianity: Social Science Approaches, Alta Mira Press, Walnut Creek, CA 2002, 511-527.

9 Andrew Lintott, Imperium Romanum, Politics and Administration, Routledge, London - New York 1993, véase el capítulo de "tasación y prestaciones personales" pp. 70-96. B. Shaw, Roman Taxation, en: Michael Grant - Rachel Kitzinger (eds.). Civilization of the ancient Mediterranean: Greece and Rome. 3 vols., Scribner, New York 1988, 809-827.

10 W. Rebell, фópos en: Horst Balz - Gerhard Scheider, Diccionario exegético del Nuevo Testamento, vol. II, Sígueme, Salamanca 1998, 1989s. cf. Pauly-Wissowa VII, A 1 78, esp. 44-47. Lucas emplea el concepto griego фópos en su texto paralelo (Lc 20,22), vocablo que usa también en su material propio cuando Jesús es acusado de prohibir pagar a los judíos el tributo (Lc 23,2).

11 Este latinismo aparece en griego, arameo y hebreo. K. Weiss, фópos, en: ThWNT IX (1973) 81-86: "Census ist zunächst die Erhebung des abgabeflichtigen Vermögens an Kapital, Grundeigentum u Sklaven, dann die Liste darüber, der Steuerkataster, weiterhin das steuerpflicthtige Vermögen selbst $u$ endlich die als Kopf- oder Grundsteuer zu erlegende Summe" (p. 83, n. 12). En este último sentido es empleado por Mt 17,25; 22,17.19, mientras que Lucas, Lc 2,2 y Hech 5,37, traduce la palabra correspondiente al primer significado con $\alpha$ rro $\gamma \rho \alpha \phi \eta$. 
tum soli, que gravaba la tierra y los bienes inmuebles, y tributum capitis o tributo sobre las personas (capitación). Además, existía una amplia gama

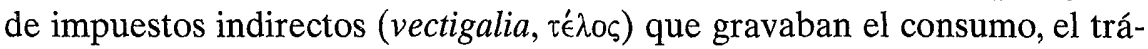
fico de mercancías, las actividades comerciales... Por regla general, el tributum de las provincias senatoriales era destinado al aerarium Saturni, mientras que el proveniente de las provincias imperiales engrosaba las arcas del fiscus.

La recaudación de los impuestos directos se encomendaba, por regla general, a las teóricas ciudades autónomas y tribus del imperio, de las que se esperaba que produjera una suma anual fija. Esa cantidad se computaba en base al tamaño de la provincia y, probablemente, al número de habitantes. En muchos casos se seguía el censo romano. La exacción era responsabilidad última del quaestor en una provincia pública o del procurador en una provincia imperial ${ }^{12}$, quienes debían asegurarse de que se recaudara a tiempo la cantidad estipulada en metálico y, en ocasiones, también en productos (especialmente trigo ${ }^{13}$ ). Las societates publicanorum para la recaudación de impuestos fueron perdiendo importancia en la época imperial, ya que las ciudades o el aparato administrativo imperial asumieron su exacción.

Los impuestos indirectos (vectigalia) eran numerosos, p.e. el impuesto de liberación de los esclavos, compra-venta de esclavos, impuesto de herencia... ${ }^{14}$ Destacaban especialmente los aranceles (portoria) que se recaudaban en los puertos, en las aduanas de las fronteras imperiales y provinciales: el gravamen fiscal en la frontera oriental de acceso al imperio era del $25 \%$ del valor de la mercancía importada, mientras que el impuesto entre provincias oscilaba entre el 2 y $5 \%$. Además de los impuestos indirectos estatales existían también otras pequeñas tasas provinciales o locales. Pero analicemos con más detalle la situación fiscal en Palestina.

$12 \mathrm{Ni}$ Augusto ni sus sucesores introdujeron el servicio de los publicani para recaudar este tipo de gravámenes.

13 Peter Garnsey - Richard Saller, The Roman Empire. Economy, Society and Culture, University of California Press, Berkeley - Los Angeles 1987, 87-88.

14 Para un análisis del tipo de impuestos romanos indirectos en Palestina cf. Werner Stenger, Gebt dem Kaiser 26-29, entre los que destacan el aurum coronarium, impuesto de la sal, impuestos de compra-venta, impuesto de tribunales, impuesto industrial. A estos impuestos indirectos hay que añadir, además, los aranceles de diversos tipos de aduanas o de tránsito, así como otros trabajos que había que prestar a la mancomunidad (angaria) y una contribución especial para el ejército (annona) (pp. 30-36). 


\subsection{Herodes y los impuestos en Judea}

Los reyes asmoneos y Herodes heredaron el sistema de impuestos existente en la tierra de Israel y en Celesiria durante los periodos tolomaico y seléucida, aunque modificaron el número y el porcentaje de los gravámenes, por lo que los súbditos judíos continuaban pagando el epikephalion o impuesto de capitación, a excepción hecha de los sacerdotes. Para esta época, Josefo no recoge quejas de parte de los súbditos judíos respecto a las prácticas de tasación.

Por el contrario, este historiador judío expresa un juicio negativo sobre Herodes y su sistema tributario en Palestina. Esta opinión ( $A J$ XVII 308; $B J$ II 85ss) ha influido de forma poco crítica en la mayor parte de las investigaciones recientes. Así, gran parte de los estudiosos modernos consideran que los judíos sufrieron una política fiscal opresiva bajo el gobierno de Herodes ${ }^{15}$. Este monarca habría esquilmado la maltrecha economía de sus súbditos judíos mediante un sistema abusivo de recaudación fiscal: a) las gravosas tasas impuestas por el propio Herodes para realizar todo su ambicioso plan de construcciones; b) el tributo que Palestina tenía que abonar a Roma y c) los impuestos religiosos para el mantenimiento del templo y de los sacerdotes (impuesto del templo y los diezmos). Sin embargo, una valoración diferente de los datos considera que la política fiscal de

15 De esta opinión es J. Klausner, The economy of Judaea in the Period of the Second Temple, en: The World History of the Jewish People VII: The Herodian Period, New Brunswick 1972, 180-205. Abraham Schalit, König Herodes 262-98; Shimon Applebaum, Herod I, en: EncJud, Keter, Jerusalem 1971, 382-5; Shimon Applebaum, Judaea as a Roman Province: The Countryside as a Political and Economic Factor, en: $A N R W$ II 8 (1977) 375-79; Idem, Economic Life in Palestine, en: S. Safrai - M. Stern, The Jewish People in the First Century. Vol. II: Historical Geography, Political History, Social, Cultural and Religious Life and Institutions (CRINT I/2), Van Gorcum - Fortress Press, Assen/Maastricht - Philadelphia 1987, 661s.; Gerd Theissen, Sociology of Early Palestinian Christianity, Fortress Press, Philadelphia 1978; Richard A. Horsley - John S. Hanson, Bandits, Prophets, and Messiahs: Popular Movements in the Time of Jesus, Winston, Minneapolis 1985, 58-63; Richard A. Horsley, Jesus and the Spiral of Violence: Popular Jewish Resistance in Roman Palestine, Harper \& Row, San Francisco 1987, 13; Marcus J. Borg, Conflict, Holiness, and Politics in the Teaching of Jesus, Edwin Mellen Press, New York 1984, 53-54; Douglas E. Oakman, Jesus and the Economic Questions of His Day (Studies in the Bible and Early Christianity), Edwin Mellen Press, New York 1986, 68-71; David A. Fiensy, The Social History of Palestine in the Herodian Period: The Land Is Mine (Studies in the Bible and Early Christianity), Edwin Mellen Press, New York 1991,100-105. Cf. Aryeh Kasher, King Herod. A persecuted persecutor: a case study in psychohistory and psychobiography (Studia Judaica 36), Walter de Gruyter, Berlin - New York, 2007, 418, quien lo compara con un dictador por sus pretensiones de grandeza visible en enormes edificaciones, cuyos costes agravaron la situación económica de sus súbditos. 
Herodes no fue más severa que la de sus predecesores e, incluso, habría sido beneficiosa para el país, ya que supuso progreso y prosperidad ${ }^{16}$.

Una posición intermedia viene defendida por otro grupo de estudiosos, tales como E. Gabba ${ }^{17}$ y Jack Pastor ${ }^{18}$. Según estos autores, Herodes no explotó su territorio con una política fiscal severa a partir del año 31 a.C. De hecho, en dos ocasiones redujo los impuestos (en los años 20 y 14 a.C.). En opinión de Jack Pastor, las tasas herodianas no fueron ni más bajas ni más elevadas que las de la administración posterior romana. $Y$ aunque Herodes, al menos en dos ocasiones, recurrió a una tasación punitiva de sus súbditos ( $A J$ XIV 433 y $B J$ I 314; $A J$ XVII 42), esas medidas extraordinarias no fueron ideadas con el objeto de recaudar más impuestos, sino de mostrar la mano dura del monarca contra los súbditos rebeldes.

En esta misma línea de pensamiento, Samuel Rocca ${ }^{19}$, en su monografía dedicada a Herodes, considera que los súbditos tuvieron que abonar impuestos relativamente elevados, especialmente al inicio de su reinado (37-31 a.C.). Durante ese primer periodo, la tasación era elevada con el objeto de obtener dinero con el que contentar a Marco Antonio y a las tropas conquistadoras. Ante el número reducido de gentiles que habitaban su territorio para someterlos a tasación y dado que Cleopatra dominaba gran parte de los recursos del país (puertos, plantaciones de bálsamo...), Herodes se encontró ante la imperiosa situación de recaudar impuestos, por lo que tuvo que imponer onerosas cargas fiscales a los ricos y, en menor medida, al campesinado judío que tenía pocos recursos económicos. Pero el año 31 a.C., tras la victoria naval de Augusto en Accio, supuso un cambio drástico en la política fiscal, ya que las tierras reales volvieron a manos del monarca, las cuales constituían la verdadera fuente de riqueza y de ingresos. Además, Octavio añadió todas las ciudades gentiles, que habían formado parte del reino asmoneo, al territorio de Herodes, socius y amicus populi romani, quien tenía un foedus aequus con Roma y no un mero tratado de

${ }^{16}$ E.P. Sanders, La figura histórica de Jesús, Verbo Divino, Estella 2000, 37-53.

17 E. Gabba, "The social" 118, hablando de Herodes afirma: "However, the charges of excessive exploitation of the kingdom, leading to general destitution, which are often accepted by modern historiography, seem to be unfounded".

18 Jack Pastor, Land, 98-126. Tamar Landau, Out-Heroding Herod. Josephus, Rhetoric, and the Herod Narratives (Ancient Judaism and Early Christianity 63), Brill, Leiden - Boston 2006, 197s. Joseph Geiger, Rome and Jerusalem: Public Building and the Economy, en: David M. Jacobson - Nikos Kokkinos (eds.), Herod and Augustus. Papers Presented at the IJS Conference, 21st-23rd June 2005 (IJS Studies in Judaica 6), Brill, Leiden - Boston 2009, 157-169.

19 Samuel Rocca, Herod's Judaea (TSAJ 122), Mohr Siebeck, Tübingen 2008, $203-$ 210 
amistad y alianza. Como consecuencia de la mejor situación económica de Palestina, la presión fiscal herodiana sobre los súbditos judíos se aligeró de forma significativa.

Herodes y su estado mantenían, por tanto, una relación especial con Roma, aunque conllevaba ciertas limitaciones. Como rey cliente de los romanos $^{20}$, su política exterior estaba totalmente limitada. No obstante, le confería la posición de dueño y señor de Palestina. Asimismo, obtuvo otros dos beneficios importantes: al igual que su padre, se convirtió en ciudadano romano y mantuvo relaciones personales y políticas de cliente respecto a Augusto, lo que le sirvió para mantenerse tanto tiempo en el poder (Josefo, AJ XV 190).

Relevante para nuestro estudio es si este tratado de amistad con Roma exoneraba a Herodes y a su reino de tener que pagar tributo al imperio. La discusión sobre las obligaciones fiscales judías hacia Roma bajo el reinado de Herodes tiene como gran escollo la ausencia de testimonios. Nuestra fuente literaria judía más importante para esa época, Josefo, no menciona que sus súbditos estuvieran sujetos al pago de tributo al imperio. A. Momigliano ${ }^{21}$, sin embargo, basó su hipótesis de que Roma continuó exigiendo un tributo anual de Judea en base a un pasaje poco claro de Apiano, Bell. civ. 5,75, interpretación que ha sido criticada por la ausencia de evidencias. Muchos exegetas de NT, no obstante, se han apoyado directa o indirectamente en esta opinión de Momigliano para mencionar de forma poco precisa "los impuestos romanos" que gravaban a los judíos o que Herodes tenía que pagar una suma fija anual a Roma. Sin embargo, no existe nada que apoye tal teoría22.

El consenso de los historiadores afirma en la actualidad que, aunque no existía una regla establecida y fija, pero en la práctica los reinos clientes/vasallos durante la República y la primera etapa del Principado no estaban sujetos a la tasación anual, ni se conoce para esa época algún rey cliente que tuviera que pagar el tributo a Roma. Así, según E. Gabba, la Judea de Herodes fue uno de los estados clientes que no tributaba a

20 Peter Richardson, Herod. King of the Jews and Friend of the Romans, University of South Carolina Press, Columbia 1996, 226-239; Anthony A. Barrett, Herod, Augustus, and the Special Relationship: The Significance of the Procuratorship, en: David M. Jacobson - Nikos Kokkinos (eds.), Herod and Augustus 281-302, considera que el nombramiento de Herodes como procurador le daría la autoridad sobre las cuestiones patrimoniales y la administración de las finanzas de Augusto en Palestina.

21 Arnaldo Momigliano, Ricerche sull'organizzazione della Giudea sotto il dominio romano, 63 a. C.-70 d. C. (Bologna: Annali della R. Scuola Normale Superiore di Pisa, 1934; repr., Amsterdam: Adolf M. Hakkert, 1967), 10-36.

22 Fabian E. Udoh, To Caesar 121. 
Roma ${ }^{23}$. Por otra parte, hay que señalar que los judíos que se reunieron tras la muerte de Herodes, exigieron de Arquelao una reducción tanto del impuesto anual como de los aranceles de ventas ( $A J$ XVII 204-5; $B J$ II 4). Posteriormente, la legación ante Augusto expuso su queja de la elevada tasación herodiana con la esperanza y el objetivo de apoyar su demanda de abolir la monarquía ( $A J$ XVII 307-8; $B J$ II 85-86). Pero para nada se menciona en ambos casos el tributo a Roma. Herodes, como otros reyes clientes y los hechos de su reinado claramente dejan traslucir, fue señor de su territorio con independencia judicial, administrativa, militar y fiscal bajo la hegemonía romana ${ }^{24}$. Impuso y suprimió impuestos ad libitum; decretó las cargas fiscales para las ciudades y colonias que había fundado, todo ello sin referencia alguna a supuestas obligaciones fiscales hacia Roma.

A nivel interno de Palestina, sin embargo, es imposible determinar el tipo de gravámenes que Herodes impuso a sus súbditos y en qué consistían. La falta de datos concretos ha ocasionado que los eruditos hayan establecido un marco teórico que permitía atribuir a este monarca y a sus hijos diferentes impuestos. Se presuponía que el rey judío, además de haber asumido aspectos del sistema fiscal romano, habría introducido diversas tasas conocidas en Egipto o Siria. Especialmente relevante en esta dirección fue la publicación de Schalit ${ }^{25}$ sobre Herodes, para quien el monarca estableció los siguientes aranceles: tributum capitis, tributum soli (impuesto de propiedad y de ingresos), impuesto de la corona, impuesto de ventas y ocupacional, aranceles de aduanas e impuestos varios. Harold Hoehner ${ }^{26}$, por su parte, expone tasaciones diferentes a las anteriores para el territorio de Herodes Antipas, que a su vez provendrían de su padre, Herodes el Gran-

23 E. Gabba, The finances of King Herod, en: A. Kasher - U. Rappaport - G. Fuks (eds.), Greece and Rome in Eretz Israel: Collected Essays, Jerusalem 1990, 160-168, aquí 164. E. Gabba, Social, Economic and Political History of Palestine 60 BCE-CE 70, en: CHJ. The Early Roman Period 3, Cambridge 1999, 121: "The often painted picture of a kingdom tragically oppressed by the double weight of taxes due to the king and the tribute paid to Rome, is tendentious in both of its elements. There is no evidence that Herod, after $30 \mathrm{BCE}$, or his heirs after him, paid any tribute to Rome, and this state of affairs coincides perfectly with what we know of the condition of the reges socii et amici populi Romani". El pago de tributum ha sido defendido por M. Stern - S. Applebaum, en The Jewish People in the First Century Vol. I, Van Gorcum - Fortress Press, Assen/Maastricht - Philadelphia 19742, 238-9; 324-334; y Vol. II, p. 661 y n. 8.

24 Fabian E. Udoh, To Caesar 144.

25 Abraham Schalit, König Herodes. Der Mann und sein Werk, Walter de Gruyter, Berlin 20012, 256-296.

${ }^{26}$ Harold W. Hoehner, Herod Antipas, Cambridge University Press, Cambridge 1972, 75-77, menciona la capitación, impuestos de pesca, aranceles de aduanas, impuestos de compra-venta, impuesto profesional, impuesto religioso. K. C. Hanson - Douglas E. Oakman, Palestine in the Time of Jesus. Social Structures and Social Conflicts, Fortress 
de. Sin embargo, este tipo de suposiciones son arbitrarias, únicamente basadas en la existencia de dichas imposiciones en otros lugares de Oriente Medio. El reino de Herodes reflejaría ciertos modelos específicos de tasación existentes en otras regiones del imperio. Ese modelo, sin embargo, estaba marcado por la adaptabilidad y variabilidad, acomodándose a las necesidades económicas y políticas.

Probablemente, Herodes eximió a los judíos en los últimos años de su reinado del tributo (фópoc o impuestos de los frutos de la tierra), dado que la situación económica había mejorado. Todos los súbditos de Herodes tendrían que pagar el epikephaleion, la capitación. Como los seléucidas, también habría mantenido los impuestos de compra-venta, los gravámenes sobre la actividad comercial: el comercio de tránsito a través de aranceles y derechos de peaje, o el impuesto profesional. Existían otros gravámenes fiscales como era el impuesto de inscripción, que se pagaba por todos los bienes antes de la exportación o importación ${ }^{27}$.

Además de hacer frente a la fiscalidad de Herodes, los judíos tenían que pagar los impuestos especiales para el mantenimiento del templo y sus sacerdotes, tales como la terumah y la ma'aseroth, y el medio shekel anual28. En el ámbito religioso, este monarca probablemente dirigió su política fiscal contra los sacerdotes y los bouleutes, en oposición a la práctica habitual de los seléucidas y asmoneos, lo cual explicaría la actitud negativa de Josefo frente a su política recaudatoria, dado que él era sacerdote. Antes de su reinado, las clases pudientes de Judea estaban exentas de la mayor parte de los impuestos, aunque es verdad que contribuían a la comunidad mediante el euergetismo voluntario. No pudiendo recaudar más impuestos de las clases humildes, Herodes optó por gravar en mayor medida a las clases adineradas, por lo que obtuvo más dinero y el control económico sobre sus súbditos. No obstante, el grueso de sus ingresos provenía de

Press, Minneapolis 1998, 144, señalan los siguientes impuestos en tiempos de Herodes: impuesto de tierra - propiedad, capitación, impuestos de mercados en las ciudades, aduanas de tránsito, aranceles portuarios y la contribución mediante trabajos comunales para proyectos del estado.

27 E. Gabba, "The social" 118: "Taxes were levied directly on the produce of the soil, through payment of a proportional or a fixed quota (there does not appear to have been a capitation tax, although the Romans later introduced one), and indirectly on sales and certain trades, in particular the transit trade, through excise duties and tolls on various commercial activities".

${ }^{28}$ Sobre los diferentes gravámenes religiosos de los judíos en tiempo de Jesús cf. Werner Stenger, Gebt dem Kaiser 147-228: impuesto del templo - shekalim; impuesto de la madera; las primicias - bikurim; contribuciones para el personal del culto: mala, teruma, ma'aser r'ishon, ma'aser min ha ma'aser; otras aportaciones: ma'aser sheni, ma'aser shlishi, ma'aser ani, p'at sade, leket y shik' $\mu a$. 
los beneficios procedentes de las tierras reales, ya que él era el mayor propietario de tierras fértiles, algunas de las cuales constituían su patrimonio personal, pero la mayor parte habían sido confiscadas a sus enemigos.

Josefo no menciona el uso de la práctica romana y helenista de los publicanos (recaudadores de impuestos) en conexión con los asmoneos ni con Herodes. Por tanto, este monarca empleó probablemente funcionarios estatales para la recaudación de impuestos, quienes recibían un salario regular. Estos agentes vienen descritos en $A J$ XVII 308 como "sus esclavos/servidores" que eran enviados a recoger el tributo. De esta forma, el beneficio de los publicanos fue eliminado del sistema fiscal.

Un elemento importante del ámbito económico lo constituía la acuñación de moneda 29 . Herodes mostró cierta reserva respecto a las representaciones y símbolos, intentando evitar las imágenes humanas y el simbolismo excesivamente sacralizado. Prosiguió con la imaginería de los asmoneos (la doble cornucopia y el pomelo), posiblemente acuñando monedas de Tiro empleadas en el ámbito local para el pago del impuesto del Templo. De igual modo, utilizó símbolos republicanos romanos mediante los que mostraba su simpatía hacia el Senado romano, a quien debía su poder. Fuera de su país, fue considerado un importante patrono, un hombre amable y generoso, piadoso y amigo de los romanos. Estas características contrastan con la imagen que presenta Josefo. En conclusión, se puede afirmar que en tiempos de Herodes, todas las clases sociales pagaban tasas de una $u$ otra forma, aunque el peso mayor de los impuestos recaía sobre la clase dominante.

Tras la muerte de Herodes, su reino fue dividido entre tres de sus hijos. El sistema tributario de esos tres territorios no se modificará respecto a Roma. Por tanto, tendrán una autonomía fiscal en la exacción de impuestos y tributos ${ }^{30}$. Esa situación permaneció en las regiones de Antipas y Filipo durante casi medio siglo. Sin embargo, la situación de los territorios gobernados por Arquelao, Idumea, Judea y Samaría, cambió en el

${ }^{29}$ A. Kushnir-Stein, Coins of the Herodian Dynasty: The State of Research, en: N. Kokkinos (ed.), The World of the Herods. Volume 1 of the International Conference The World of the Herods and the Nabataeans held at the British Museum, 17-19 April 2001 (Oriens et Occidens 14), Stuttgart 2007, pp. 55-60. Donald T. Ariel, The Jerusalem Mint of Herod the Great: A Relative Chronology, en: INJ 14 (2000-2002) 99-124; Idem, The Coins of Herod the Great in the Context of the Augustan Empire, en: David M. Jacobson - Nikos Kokkinos (eds.), Herod and Augustus, 113-126; Ya'akov Meshorer, A Treasury of Jewish Coins. From the Persian Period to Bar Kokhba, Jerusalem 2001, 5-30; Peter Richardson, Herod 203-215; Morten Hørning Jensen, Herod Antipas in Galilee (WUNT II 215), Mohr Siebeck, Tübingen 2006, 194-197.

30 Werner Stenger, Gebt dem Kaiser 56, opina, sin embargo, que pagaron un cierto tributo al erario imperial como signo de su señorío (tributario) frente a Roma. 
año 6 d.C., tras haber sido desterrado a Francia por Augusto. Solo tras la muerte de Agripa I (44. d.C.), en cuyo reino habían sido integradas esas tetrarquías, Palestina quedó bajo dominio directo romano, tanto político como fiscal.

\subsection{Judea bajo administración directa romana (6 - 41 d.C.)}

Una vez depuesto Arquelao de su cargo, sus dominios pasaron a depender directamente de la administración romana ${ }^{31}$. No obstante, el nuevo régimen político de esos territorios no es muy preciso conforme a las informaciones que trasmite Josefo. Así, por una parte, el historiador judío señala que "Augusto agregó luego a la provincia de Siria el territorio que había estado sometido a las directrices de Arquelao. E inmediatamente fue enviado allá por el emperador un hombre perteneciente al orden consular, Quirino, con la misión de proceder al censo de las propiedades existentes en la referida provincia de Siria y de vender el patrimonio de Arquelao" ( $A J$ XVII 335). Por consiguiente, Judea fue anexionada a la provincia imperial de Siria y sometida al legado imperial de rango senatorial. El historiador judío silencia el censo propio de Judea, considerando que se realizó más bien un censo en toda Siria. Sin embargo, el mismo autor indica en otro pasaje que Judea fue vinculada a Siria, pero sin integrarse totalmente en ella: se le otorgó un gobernador propio de rango ecuestre, quien tenía toda la potestad militar, jurídica y fiscal, exceptuando solamente en algunas materias en las que estaba subordinado al legado imperial de Siria ${ }^{32}$.

Estas dos noticias vienen combinadas en otro párrafo de Josefo: "Quirino, perteneciente al orden senatorial..., se presentó en Siria, adonde fue enviado por Augusto para administrar justicia entre las gentes y para efectuar el censo de sus propiedades. Y con él fue enviado también Coponio, perteneciente al orden ecuestre, para gobernar a los judíos con poderes absolutos. También Quirino se presentó en Judea, al haber sido agregada ésta a la provincia de Siria, para llevar a cabo el censo de las propiedades

31 Israel Shatzman, L'integrazione della Giudea nell'impero romano, en: Ariel Lewin (ed.), Gli Ebrei nell'impero romano, La Giuntina, Firenze 2001, 17-46.

32 BJ II 117: "El territorio de Arquelao fue convertido en provincia y fue enviado como procurador Coponio, que pertenecía a la clase ecuestre de los romanos, y recibió de César todos los poderes, hasta el de condenar a muerte. Durante su gobierno, un galileo llamado Judas, incitó a sublevarse a los habitantes del lugar, pues les reprochaba que soportasen el pagar tributos a los romanos". 
judías y para vender los bienes de Arquelao. Y los judíos, aunque al principio no querían en absoluto oír hablar de catastro, fueron cediendo en lo más de su oposición" ( $A J$ XVIII 1-2).

Podemos concluir que en el año 6 d.C., P. Sulpicio Quirino fue nombrado legatus Augusti pro praetore en la provincia imperial de Siria, y como tal detentaba todo el poder jurídico, fiscal y militar. Ese mismo año, al asumir sus funciones, realizó el censo rutinario en Siria. Al mismo tiempo, le fue encomendado organizar, tras la anexión romana de los antiguos territorios de Arquelao, el primer censo ${ }^{33}$ romano de los habitantes de la nueva provincia y de sus bienes (Lc 2,2; Hech 5,37; Josefo, $A J$ XVII 13,4; XVIII 12), lo que constituyó la base catastral para que los judíos pagaran por primera vez en su historia el tributo directamente al emperador. Se trataba de un procedimiento normal de la administración romana, condición necesaria para la imposición del impuesto de capitación. Aunque ese censo no se identificaba con el que se debía realizar en Siria, Quirino, sin embargo, fue comisionado, como encargo especial, de liquidar las propiedades de Arquelao, bien mediante venta o arrendamiento de tal forma que fueran útiles al fiscus del emperador.

Se concluye, por tanto, que Judea no fue incorporada a Siria, sino que se creó con ella una nueva provincia romana de segunda categoría ${ }^{34}$, de las llamadas "provincias procuratorianas", gobernada por un magistrado del orden ecuestre, es decir, inferior al orden senatorial, que recibía el título de prefecto, según consta en una inscripción hallada en el teatro de Cesarea, en la que se cita a Poncio Pilato como praefectus Iudaeae; probablemente después del año 44, este título se cambió al de procurador. Solo determinadas provincias, que eran conflictivas o difíciles de gobernar y de forma excepcional, se ponían bajo gobierno directo de un procurador de rango ecuestre $^{35}$. Judea es así una provincia autónoma, cuyo prefecto poseía la completa autoridad sobre la zona. La intervención del legado imperial de

33 F.X. Steinmetzer, Census, RAC II, 969ss: „Als erste Prokurator Judaeas wurde etwa 6/9 nC. Coponius, als Legatus von Syrien Quirinius nach Judea gesandt. Dieser nahm iJ. 37 der aera Actiaca d.h. 6/7 nC. einen C. vor". Jack Pastor, Land and Economy 136140. Sobre el censo de Quirino (Lc 2, 1-5), cf. el apéndice de Emil Schürer, Historia del pueblo judío. Vol. I, 515-550.

34 Así la considera Joaquín González Echegaray, Los Herodes. Una dinastía real en tiempos de Jesús, Verbo Divino, Estella 2007, 121s. Por su parte, Werner Stenger, Gebt dem Kaiser 58, la considera una provincia de tercera clase (cf. Strabo 17,3,25: "A algunas provincias, el emperador enviaba encargados a hombres de rango consular; a otras, hombres de rango pretorio y a otras, de rango ecuestre").

35 Emil Schürer, Historia del pueblo judío en tiempos de Jesús 175 a.C.-135 d.C. Vol. I: Fuentes y marco histórico, Ed. Cristiandad, Madrid 1985, 463: "Y esta categoría debe 
Siria, Quirino, constituyó un caso único, explicable porque los romanos no disponían de su propio aparato administrativo en la nueva provincia. Además, este legado imperial tenía experiencia previa ya que había pacificado la zona tras la muerte de Herodes el Grande y la sucesión de sus hijos.

El censo ordenado por los romanos despertó conmoción y resentimiento en el pueblo judío. La deposición y el destierro de Arquelao, la anexión del territorio, el censo y la imposición del tributo provocaron una rebelión ( $B J$ II 118). El motivo específicamente religioso, que parece haber sido predominante, de la ilegalidad del censo fue estrechamente asociado con un segundo motivo de carácter más político. El censo y el impuesto consecuente de capitación fueron vistos como pruebas de la pérdida de independencia y de esclavitud ante un poder extranjero.

Como territorio anexionado al imperio, Judea pasó a ser stipendiariae, es decir, sujeto a tributo, por lo que todos los varones fueron sometidos a un doble impuesto directo: a) el tributum soli, vinculado al solar familiar, que implicaba el pago de la suma correspondiente en función del registro catastral. Las fuentes existentes no proporcionan detalles sobre la organización del tributum soli en Judea, por lo que no sabemos si este impuesto gravaba únicamente la propiedad o también su producción anual; es probable que se asemejara al impuesto herodiano sobre los productos de la tierra y fuera recaudado en su mayor parte en especie. b) Tras el censo de población se agregó un nuevo impuesto gravoso de capitación (tributum capitis), que debían pagar las personas como tales, independientemente de sus bienes. Según González Echegaray, el impuesto territorial ya existía en tiempos de Herodes, pero el impuesto personal resultaba una novedad para los judíos 36 .

La existencia del impuesto de capitación en Judea durante la vida de Jesús se desprende de la palabra $\hat{\nu} \nu \sigma o \varsigma$ en los pasajes del NT, la cual aparece sólo en Mc 12,14; Mt 22,17.19 y Mt 17,25, donde Jesús, al comentar la petición sobre el impuesto del templo (didracma), pregunta a Simón, "¿de quién reciben los reyes de la tierra peaje o tributo"37. Los historiadores y

considerarse como una excepción a la regla. La mayoría de las provincias imperiales, al igual que las senatoriales, estaban administradas por personas de rango senatorial, las mayores (como Siria) por antiguos cónsules, y las más pequeñas por antiguos pretores. Sólo unas pocas provincias estaban excepcionalmente bajo mando de gobernadores de rango ecuestre, a saber, aquellas que, debido a sus dificultades, a la individualidad de su cultura o a su carencia de ella hacían poco menos que imposible el estricto cumplimiento de las regulaciones ordinarias del Imperio".

36 Joaquín González Echegaray, Los Herodes 122.

37 "Significa impuesto de capitación" escriben Davies y Allison sobre la expresión ol

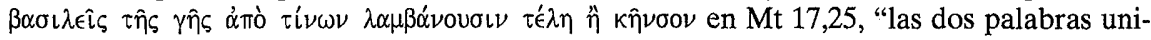


estudiosos del NT consideran que esta perícopa evangélica proporciona una evidencia irrefutable para defender que los judíos tenían que pagar el impuesto de capitación a Roma desde el censo romano realizado en el año 6 d.C. 38 Así leemos afirmaciones: "En la época de Tiberio", -escribe Heichelheim- "Judea pagaba un impuesto de capitación de un denario, que había sido introducido tras la deposición de Arquelao y la confiscación de su reino"39. Como prueba para defender su opinión, Heichelheim cita Mc 12,13-17 y los textos paralelos (Mt 22,15-22 y Lc 20,20-26). Esta opinio communis, sin embargo, ha sido cuestionada recientemente por Fabian E. Udoh, para quien el término "censo" indica simplemente la lista de los habitantes del territorio, sin implicar el pago del tributo de capitación ${ }^{40}$.

Contra la hipótesis de Fabian E. Udoh, se puede aducir, no obstante, un texto de Filón. En el año 40 d.C., Agripa, según informa Filón, escribe a Gayo con la siguiente petición: "Por mi naturaleza y por la multitud de beneficios con que me has enriquecido, me habría atrevido a pedir para mi patria, si no la ciudadanía romana, al menos la libertad (independencia) y la remisión de los impuestos, pero no he tenido la osadía de pedir nada de eso..." (Legat 287). Judea, la patria de la que habla Filón, había estado bajo dominio directo de Roma y sometida a tributo desde el año 6 d.C. "Libertad" y "remisión de tributo" (la concesión más alta que se podía conceder a las provincias) habría supuesto la liberación de Jerusalén y del resto de Judea de la administración directa romana junto con la concesión de inmunidad fiscal.

Por desgracia, desconocemos la forma de fijar y la cuantía monetaria del tributo de capitación, pues el supuesto denario anual por persona, tal y como pudiera dar a entender Mc 12,13-17, es cuestionable, como posteriormente veremos. A los impuestos directos, hay que añadir el resto de los impuestos indirectos anteriormente mencionados y los posibles impuestos locales ${ }^{41}$. En opinión de Josefo, Judea volvió a tener el mismo sistema

das implican los impuestos directos e indirectos, es decir, de todo tipo (cf. Rom 13,7, donde фópos y té̉ and Exegetical Commentary on the Gospel according to Saint Matthew, Vol. III, T.T. Clark, Edinburgh, 1997, 211

38 Cf. (1) la declaración de Apiano, Syr. 11.8.50; (2) el episodio del impuesto al César de los evangelios; y (3) el pasaje del jurista Ulpiano sobre el registro del censo y la notificación del jurista Pablo sobre la fundación de la colonia romana en Cesarea.

${ }^{39}$ F.M. Heichelheim, Roman Syria, en Tenney Frank (ed.), An Economic Survey of Ancient Rome, Vol. 4, Baltimore 1938, 236, n. 33.

40 Fabian E. Udoh, To Caesar 221s.

41 Referente a los impuestos de compra-venta Josefo, $A J$ xvii 205. Sobre los productos agrícolas traídos a Jerusalén, $A J$. xviii.90; sobre el impuesto de las casas en Jerusalén, $A J$ xix 299 (es probable que fuera impuesto por algún prefecto romano como medida de 
administrativo que Pompeyo ${ }^{42}$ había establecido en el año 63 a.C. (y que perduró hasta el 40 a.C.), es decir, un gobierno directo en manos de la aristocracia sacerdotal y un gobierno indirecto supervisor al mando de un magistrado romano.

\section{El sistema de la recaudación de impuestos en Judea}

El sistema de recaudación de impuestos en la provincia de Judea sigue siendo elusivo. El estudio clásico, al menos entre los estudiosos de NT, de John R. Donahue 43 sobre los recaudadores de impuestos en tiempos de Jesús se basa en la noción de que "los impuestos directos, en ese momento, estaban bajo la supervisión de la autoridad central", mientras que los impuestos indirectos, los aranceles, peajes y otros impuestos, fueron encomendados a arrendatarios individuales. En su opinión, por lo tanto, durante el gobierno de los prefectos y procuradores, los impuestos directos, el impuesto de capitación y el impuesto sobre la tierra, no fueron subcontratados o arrendados. Los funcionarios encargados de recaudar estos gravámenes fiscales estaban bajo la supervisión directa de los romanos. No obstante, esta visión no ha sido compartida por todos los estudiosos ${ }^{44}$.

¿Cómo y quién cobraba en tiempos de Jesús los impuestos directos en Judea? El sistema de recaudación de los impuestos mediante su arrendamiento funcionó en ese territorio ${ }^{45}$ durante un periodo breve de tiempo desde Pompeyo hasta Gabinio, pues poco tiempo después, Julio Caesar abolió en Judea el sistema de exacción por medio de publicani y, en consecuencia, el sistema clásico de publicanos dejó de existir en Palestina. Herodes instituyó, como anteriormente habían hecho los reyes asmoneos, sus propios servicios de recaudación fiscal. Es poco probable que con la constitución de la nueva provincia se volviera a instaurar un sistema obsoleto de recaudación.

\footnotetext{
castigo por alguna de las confrontaciones con el poder romano, aunque desconocemos el motivo exacto para dicha tasación, la cual fue suprimida por Agripa I (AJ XIX 299).

42 No obstante, el estatuto del 'estado judío' había sufrido ciertos cambios desde Pompeyo hasta Herodes (40 a.C.), en virtud de las concesiones realizadas por los magistrados romanos, especialmente Julio César.

43 John R. Donahue, Tax Collectors and Sinners: An Attempt at Identification, en: $C B Q 33$ (1971) 48-49.

${ }^{44}$ Fabian E. Udoh, To Caesar 230-232.

45 Sobre la administración provincial romana cf. A. Lintott, Imperium Romanum 7980 , sobre los publicanos en Judea, pp. 156-157, cfr. la discusión de la ley romana y judía en la administración provincial.
} 
Dado que Judea constituía un pequeño territorio vinculado de alguna forma a la provincia de Siria y no de vital importancia a nivel estratégico en la frontera oriental, la administración imperial concedió pocas tropas al prefecto. Por tanto, éste necesitaba un cuerpo institucional en quien pudiera delegar la responsabilidad de recaudar los impuestos. Además, un gobierno estable era únicamente posible con la cooperación de los líderes locales. Esta práctica de cooperación con las élites locales era habitual en la administración romana, ya que éstas, gracias a su prestigio ante el pueblo, mantenían mejor el orden público y poseían conocimientos para recoger las estadísticas del censo. Como contrapartida, esperaban obtener de Roma ciertas compensaciones económicas o privilegios.

La exacción fiscal recayó presumiblemente en el Sumo Sacerdote y el Sanedrín (BJ II 405) ${ }^{46}$, quienes para desempeñar esa función contarían con un grupo de colaboradores (un secretario y la nominación de 10 hombres dirigentes, dekaprætoi) ${ }^{47}$. Josefo parece sugerir que los magistrados y los miembros del Sanedrín recaudaban personalmente el tributo. Al menos, ya deja entrever que el Sumo Sacerdote desempeñó un papel relevante en la organización del primer censo ( $A J$ XVIII 3), lo que le granjeó la estima de la clase poderosa simpatizante de Roma. Probablemente, la aristocracia sacerdotal jugaba un papel de supervisión, mientras que sus agentes recaudaban el tributo de los campesinos, pues sabemos que tenía sus propios "esclavos" y "sirvientes" para la colecta de los diezmos ( $A J$ XX 181, 206-7). Es posible que esas mismas personas hubieran sido sus agentes para la exacción del impuesto de capitación o fuera encomendado a personas relevantes de las aldeas.

Este sistema de recaudación viene corroborado por la información disponible para la época de Gesio Floro durante la revuelta contra Roma, en la que los impuestos no venían cobrados por una sociedad arrendataria de recaudación fiscal o por medio de sus propios recaudadores, sino mediante los "magistrados y los miembros del consejo", quienes iban por las aldeas recaudando el tributo. De entre los "magistrados y notables judíos", el procurador elegía a los que debían colectar los impuestos de la región ( $B J$ II 405-407). Esto indica que los exactores eran judíos al servicio del poder dominador extranjero, sin que hubiera cobradores romanos en la provincia de Judea en tiempos de Jesús.

46 E. P. Sanders, "Jesus' Galilee", en: Ismo Dunderberg et al. (eds.), Fair Play: Diversity and Conflicts in Early Christianity, Brill, Leiden 2002, 6-9; E.P. Sanders, Judaism 170-89.

47 Cf. K.C. Hanson - Douglas E. Oakman, Palestine 115. 
Por su parte, el gobernador subastaría los impuestos indirectos, quedando éstos en manos de publicanos nativos ${ }^{48}$, es decir, los arrendatarios y sus agentes eran judíos. Así, los dos recaudadores de impuestos indirectos ${ }^{49}$ conocidos por sus nombres en los evangelios son también judíos: Leví $/$ Mateo (Mc 2,17 / / Lc 5,27-32; Mt 9,9-13); y Zaqueo (Lc 19,1-10). Otro caso conocido es Juan, el publicano, uno de los notables o líderes judíos de Cesarea en tiempos del procurador Floro ( $B J$ II 287.292) ${ }^{50}$. Este sistema fiscal continuó décadas más tarde, ya que los rabinos discuten el caso de si un compañero fariseo puede convertirse en cobrador de impuestos. Si realiza esta función, se le considerará como excluido de la comunidad y no podrá volver a ser aceptado dentro del grupo de los fariseos una vez que haya abandonado el cargo (b. Bekh 31a). No obstante, estos recaudadores fariseos no vendrán condenados moralmente, pues en ocasiones ayudaban a su gente y defendían los intereses de su pueblo, cosa que no haría un exactor pagano. Se puede concluir, por tanto, que los agentes judíos de impuestos desempeñaban su cargo en cooperación o, mejor, bajo el control de los paganos que estaban al servicio del procurador.

Martin Goodman se percata de la dificultad de explicar que estos publicanos judíos fueran considerados pecadores y mal vistos en las fuentes judías y cristianas, mientras que esa crítica no se emite contra el Sumo Sacerdote y sus colaboradores directos, que cooperaban más estrechamente con Roma y se lucraban a mayor escala con los impuestos directos ${ }^{51}$. Serán los sublevados en el año 66 d.C., sin embargo, quienes consideren a todos los recaudadores de impuestos como colaboradores de los paganos.

La carga total de los impuestos debió ser gravosa ${ }^{52}$ entre las clases menos pudientes. El pago del tributo suponía, además de una carga econó-

48 Lc 19,1. Para la presencia de publicanos en la tetrarquía de Antipas, véase Mc 2,14; Mt 9,9; Lc 5,27; Harold W. Hoehner, Herod Antipas 77-9.

49 Los recaudadores de impuestos del NT no eran encargados de recoger los impuestos directos, sino los aranceles, es decir, "funcionarios o empleados en el centro de recaudación (telonion), así como también el hombre rico que adquiere el derecho de recaudar esos aranceles".

${ }^{50}$ Martin Goodman, The Ruling Class of Judaea: The Origins of the Jewish Revolt against Rome A. D. 66-70, Cambridge University Press, Cambrigde 1998, 38ss., 131.

51 Martin Goodman, The Ruling Class of Judaea 132, ofrece la siguiente explicación: los recaudadores de impuestos lograron el poder solo a través del mecenazgo romano, sin que cumplieran ninguno de los criterios generalmente aceptados por los judíos, como eran el buen nacimiento o los deseos de conocer la Torá. El poder de los publicanos era, por tanto, inmerecido.

52 Pheme Perkins, Taxes in the New Testament, en: The Journal of Religious Ethics 12 (1984) 182-200, muestra cómo el pensamiento cristiano sobre los impuestos estuvo marcado por un contexto donde los tributos eran opresivos y administrados de forma abusiva; los textos instan al respeto por el gobierno. 
mica, un reconocimiento tácito de la legalidad de las instituciones opresoras y constituía un símbolo de falta de libertad nacional incompatible con la identidad del pueblo de la alianza. Para más inri, ese dinero servía para mantener la presencia opresora romana y contribuía al esplendor de sus abominables cultos, de forma especial del culto al emperador.

A la luz de estas implicaciones, los judíos piadosos veían con malos ojos tener que tributar a Roma. Así lo entendieron varios judíos que se negaron a acatar la imposición del censo (Judas de Galilea: Josefo, BJ II 8,1; VII 6,1-4), negándose a confesar al emperador como su señor y reprochando a sus compatriotas someterse al tributo y ser sumisos a Roma ( $A J$ XVIII 25), en lugar de a Dios ( $B J$ II 118). Este rechazo de los impuestos romanos se basaba en la creencia de que aceptar el censo significaba reducir el pueblo de Judea a un tipo de esclavitud que desde el punto de vista teológico, político y económico era una condición intolerable para una nación cuyo Dios constituía el único Señor del universo. Un segundo efecto de esta campaña abierta en contra del censo fue presentarse como defensor tanto de una guerra de liberación contra Roma como de una cruda crítica contra los colaboracionistas de la potencia extranjera, ya que no eran leales ni fieles a la ley de Dios. A los ojos de los romanos, esta actitud constituía una rebeldía, una sedición pública y una ofensa digna de muerte. La superioridad de la fuerza militar romana impuso el pragmatismo de acatar ese impuesto, por lo que los judíos no tuvieron otra alternativa.

\section{Las formas de pago de los impuestos}

Hanson y Oakman ${ }^{53}$ analizan las funciones sociales del dinero (de oro y plata) en Palestina. En primer lugar, este tipo de moneda constituía un medio de acumulación de riqueza y capital por parte de los ricos (Mt 2,11; $10,9)$, quienes controlaban su posesión. El resto de la sociedad, especialmente los campesinos, estarían familiarizados con las monedas de bronce pensadas para las transacciones del mercado cotidiano (en las provincias) y preferían los intercambios de mercancías (el sistema de trueque). En segundo lugar, el dinero servía como medio de pago, ya fuera de impuestos o de transacciones económicas. El uso de las monedas de oro y plata en Judea se circunscribiría al comercio de importación - exportación, a los trabajadores estatales que recibieran sus salarios en dicha moneda y a la

${ }^{53}$ K. C. Hanson - Douglas E. Oakman, Palestine 121. 
aristocracia de Jerusalén ${ }^{54}$. Sin embargo, la mayor parte del campesinado no estaba familiarizado con la moneda del denario (un aspecto para cuestionar la historicidad de Mc 12,16) y si llegaba a sus manos, pronto regresaría a los agentes del emperador ${ }^{55}$.

Estas dos funciones sociales del dinero estaban realmente disponibles sólo para las élites y sus agentes, quienes poseían cantidades suficientes de dinero para que la funcionalidad monetaria fuera real. Por el contrario, la mayoría de la población administraría sólo monedas adquiridas con la venta de sus productos agrícolas o artesanales, que pronto las tendría que volver a poner en circulación para satisfacer las necesidades básicas o hacer frente a las deudas pendientes. Las nuevas realidades políticas imponían ahora una monetización de bronce y hacía obligatorio su uso (especialmente mediante el endeudamiento o por los impuestos indirectos exigidos que se pagaran en metálico). Ello implicaba que el sistema tradicional de trueque fuera perdiendo fuerza. De esta forma, la autoridad política podía valorar mejor y tasar la producción agrícola y maximizar los ingresos en concepto de impuestos.

Por lo que respecta a los impuestos directos, parece ser que no era indispensable pagarlos en metálico. Los campesinos podían abonar a los recaudadores locales mediante frutos en especie, quienes vendían a su vez el producto de tal forma que pudieran pagar al procurador la cantidad estipulada en metálico o incluso en grano, como posteriormente veremos. Es difícil establecer la ratio anual a lo largo del imperio entre la recaudación de los impuestos directos en metálico y en especie, pero probablemente el pago en mercancía sobrepasaba el pago en metálico en los inicios del Principado. No obstante, Mc 12,13-18 deja entrever en Jerusalén la exigencia del pago a Roma en metálico y con moneda romana. ¿Se trata esta presentación de una realidad histórica en tiempos de Jesús o refleja el contexto vital del evangelista o de la comunidad que lee ese evangelio? A estas cuestiones dedicaremos el resto del artículo.

54 Los contratos de deudas también se escribían en Palestina en términos de denarios, así como las sanciones. Los evangelios conocen y están familiarizados con las deudas en denarios (Lc 7,41 o Mt 18,28). Generalmente se ha asumido que el salario medio en tiempos de Jesús era un denario, pero esta indicación sólo aparece en conexión con grandes propiedades agrarias (Mt 20,9-10).

55 K. C. Hanson - Douglas E. Oakman, Palestine 124s. 


\section{El relato de Marcos 12,13-18}

Tras tres días de actuación en Jerusalén, se relata una serie de controversias en las que Jesús aparece como maestro que discute sobre diversos temas con sus interlocutores: el pago de impuestos al emperador, la resurrección de los muertos y el mandamiento más importante. Su gran ingenio en la argumentación deja desconcertados a los adversarios. Un ciclo de relatos de disputa (Streitgespräche) ya había sido colocado por Marcos al inicio de su actividad pública en Galilea (Mc 2,1-3,6). Este otro ciclo de controversias, donde los discípulos no desempeñan ningún papel relevante, aparece situado al final del ministerio de Jesús. De forma similar al ciclo galileo, Mc ha situado el ciclo jerosolimitano $(11,27-12,37)$ después de los sucesos iniciales del ministerio de Jesús en Jerusalén (entrada triunfal, maldición de la higuera y purificación del templo en 11,1-25), pero antes de los decisivos acontecimientos de la muerte y resurrección.

El inicio de este ciclo de controversias viene ubicado en el templo de Jerusalén, donde tiene lugar una discusión con "los jefes de los sacerdotes, los maestros de la ley y los ancianos" (Mc 11,27). Estos adversarios, tras escuchar la parábola de los labradores homicidas (Mc 12,1-11), deseaban apresarlo, sin embargo lo dejaron y se marcharon, porque tenían miedo de la gente (v. 12). Sin indicación temporal precisa ni cambio de lugar, prosigue el relato diciendo que "estos" (presumiblemente los líderes judíos mencionados en 11,27) enviaron entonces a algunos de los fariseos y de los herodianos con el fin de cazarlo con alguna pregunta capciosa. Por su parte, unos saduceos aparecerán como los interlocutores directos de la siguiente perícopa referida a la resurrección de los muertos (v. 18). Estas tradiciones recogidas en el capítulo 12 pasan revista a los diversos adversarios de Jesús, lo cual "pone de relieve la intención del evangelista que trata de poner de manifiesto que todos estos diversos interlocutores no estaban en condiciones de demostrar que Jesús hubiera cometido culpa o incorrección alguna"56. J. Meier expresa también una opinión semejante: "Con todos los artificios y vínculos de que se sirve Marcos, cuando son examinados uno a uno los relatos de disputa que componen el ciclo jerosolimitano, éste resulta ser un cajón de sastre en mayor medida, por cierto, que el ciclo galileo"57. Pero expongamos brevemente el desarrollo argumentativo de la tercera perícopa del ciclo $(12,13-17)$ correspondiente a la pregunta sobre el pago del tributo al césar.

56 J. Gnilka, El evangelio 180.

57 John Meier, Un judío marginal, vol. III 426. 


\subsection{La construcción del relato}

El relato constituye un diálogo irónico desde el inicio al final, cuyo desarrollo está magníficamente tramado, hasta el punto de que algún autor ha considerado que se trataría de un texto rabínico enteramente sometido a las reglas retóricas en uso dentro de esa literatura ${ }^{58}$. Los interlocutores de Jesús plantean la cuestión con el objeto de cazar a Jesús mediante una pregunta capciosa. Para ello comienzan con unas afirmaciones irónicas y aduladoras, lejos de una simple captatio benevolentiae (v. 14). Es sarcástico que estos emisarios de los sumos sacerdotes sepan que Jesús es un maestro que enseña el "verdadero camino59 de Dios", cuando previamente los mismos líderes religiosos demuestran su desconocimiento acerca de la persona de Jesús (Mc 11,33).

La trampa está cuidadosamente preparada, pues ya la adulación aducida de que Jesús no tiene en consideración la apariencia de las personas puede implicar una respuesta negativa incriminatoria. Esa indicación se hace eco de la afirmación en 1 Sam 16,7, cuyo contexto tiene que ver con la sustitución de un rey (Saúl) por otro (David), tema similar al de nuestro texto (césar - Cristo). Según 1 Sam, David será el antepasado del mesías y éste actuará como Dios, en cuento que ignorará las apariencias de las personas a la hora de emitir sus juicios. Si Jesús es el mesías, lo cual parece haber sido sugerido en Mc 11,1-19 (15-19), entonces tampoco tendrá en consideración las apariencias y dignidades humanas a la hora de emitir su dictamen. Además, un texto judío del siglo I procedente de Qumran, 4QpI$\mathrm{sa}^{\mathrm{A}}$ (4Q161) 8-10 3:1-25 [1-29], considera al mesías de Isa 11, quien ignora las apariencias, como el azote de los romanos, es decir, ese guerrero militante contra los enemigos de Dios ${ }^{60}$. Por tanto, si Jesús es verdaderamente Mesías, debería someter a los romanos (cf. Ps. Sal 17,30) y rechazar el pago del tributo a Roma (cf. Lc 23,2, donde se le acusa a Jesús de proclamarse rey y de prohibir pagar el tributo al emperador). La exacción del tributo implica de forma tácita reconocer no sólo la soberanía de los romanos en Palestina, sino también el status divino del emperador, lo cual va en contra del primer mandamiento judío. En este contexto, la insinuación de los interlocutores según la cual Jesús no respeta las apariencias humanas, parece ser una provocación deliberada para que cometa lesa majestad al deni-

58 D.T. Owen-Ball, Rabbinic Rhetoric and the Tribute Passage (Mt 22:15-22; Mk 12:13-17; Lk 20:20-26, NT 35 (1993) 1-14.

${ }^{59} \mathrm{La}$ referencia al camino de Dios nos trae a la mente la autodenominación cristiana como el Camino (cf. Hech 9,2.23; 24,14.22).

60 Joel Marcus, Mark 8-16, 818. 
grar la imagen idolátrica del emperador acuñada en la supuesta moneda del tributo. La gravedad de tal acción viene recogida en un ejemplo de Filostrato para el tiempo de Tiberio (Vida de Apolonio 1,15).

“¿Es lícito pagar tributo al César, o no?”. Esta pregunta sitúa a Jesús ante un dilema religioso y político. La licitud de ese acto se debe entender bajo la premisa religiosa de si Dios, según la ley mosaica, lo permite. El objeto de la cuestión es el pago del impuesto que tienen que hacer los habitantes de Judea con una edad comprendida entre los 14 y 65 años. Los interlocutores no simplemente están preguntado por una posición teórica, sino por una directriz práctica de actuación ("¿pagamos o no pagamos?" v. 14). La población de Judea detestaba los tributos romanos, no sólo porque representaban la sumisión judía a un poder gentil extranjero, sino que además el pago de esos impuestos implicaba el apoyo, aunque no deseado, de lo que representaba el emperador, es decir, su soberanía y divinidad, lo cual estaba plasmado en el poder de las imágenes de las monedas ${ }^{61}$. Existen buenas razones para pensar que los judíos eran reacios a la exigencia del pago de sus impuestos con este tipo de moneda, en caso de que su exacción tuviera que realizarse en metálico. El denario no simplemente presentaba al emperador como el oficial de mayor rango dentro de la religión el imperio romano (pontifex maximus), sino que él mismo se convertía en objeto de esa religión. Él es hijo del deificado Augusto y Tiberio mismo es Augusto, es decir aquel que merece ser servido con reverencia divina. La corona de laurel sobre su cabeza lo asocia con los dioses Apolo y Zeus. La moneda, pues, no es un simple instrumento económico o de transacción y del sometimiento político judío a Roma, sino también forma parte de la configuración del culto imperial durante el primer siglo62.

Si Jesús declaraba ilícito para un judío observante de la ley pagar los impuestos al emperador, inmediatamente habría obtenido la aclamación y el apoyo del pueblo, pero se habría posicionado en una situación precaria frente a las autoridades políticas y, en último término, ante las autoridades religiosas encargadas de recaudar ese impuesto, que conllevaba pingues

61 Sobre el poder y mensaje de las monedas (patronazgo divino y Victoria) de las monedas de Octavio Augusto cf. Paul Zanker, The Power of the Images in the Age of Augustus, University of Michigan Press, Ann Arbor 1990, 53-57, monedas que todavía estaban en circulación en Palestina en ese tiempo.

62 Larry J. Kreitzer, Striking New Images. Roman Imperial Coinage and the New Testament World (JSNTS 134), Sheffield Academic Press, Sheffield 1996, 69-98 sobre la apoteosis de los emperadores romanos en la numismática y su impacto en el judaísmo; cf. Hans-Josef Klauck, The Religious Context of Early Christianity: $A$ Guide to GraecoRoman Religions, Fortress Press, Minneapolis 2003, 29; Paul Zanker, The Power 98. 
beneficios. Dada la reciente "entrada triunfal" en Jerusalén, es probable que muchos esperaran que Jesús declarara ilícito ese pago. Por otra parte, si Jesús afirmaba la licitud del pago de los impuestos al imperio, la multitud y varios de sus seguidores se habrían sentido defraudados. Una vez desacreditado ante el pueblo, la clase sacerdotal podía ignorarle más fácilmente.

Tras esas palabras aduladoras, Jesús reconoce inmediatamente la estratagema que encierra la pregunta, así como su hipocresía, por lo que responde de forma indirecta y poco precisa, lo cual ha ocasionado que los estudiosos hayan propuesto diversas interpretaciones para esa respuesta "críptica/velada". En su lugar, pidió que le trajeran un denario, lo que pudiera indicar que no llevaba ese tipo de moneda encima. De ello, sin embargo, no se puede concluir que Jesús mostrara un desprecio radical al dinero como posteriormente se afirmó de algunos rabinos ${ }^{63}$. Los interlocutores "llevaron" un denario. Este verbo "llevar" pudiera inducir a pensar que incluso los mismos emisarios tuvieron que buscarla, porque no la tenían consigo ${ }^{64}$, considerando algún autor que la podrían haber obtenido de los cambistas del templo65. Además, se ha cuestionado que los interlocutores pudieran llevar una moneda romana en sus bolsillos, especialmente los fariseos, ya que a nivel del relato se encontraban en el recinto del Templo, sobre suelo sagrado. Por este motivo, Gnilka cree improbable que el relato premarcano situara la acción en el templo, aunque el evangelista lo haya presupuesto (cf. 14,49)66. Tras recibir la moneda, Jesús la mostró a sus inquisidores, replicando a su vez con la pregunta irónica, "¿De quién es esta imagen e inscripción?". A la respuesta esperada, "del César", contestó, "dad al César lo que corresponde al César y a Dios lo que pertenece a Dios".

El relato, tal y como se encuentra ahora, es parte de la narración del evangelio de Marcos. En la estructura narrativa, el incidente tiene lugar en

${ }^{63}$ Rabí Menajem bar Simai fue considerado un personaje piadoso "porque jamás contempló una moneda" (bPes 104a). Cf. J. Gnilka, El evangelio 178.

${ }^{64}$ E. Lohmeyer, Das Evangelium des Markus, MeyerKEK 1/2 Ergänzungshefts, 16. Aufl., Vandenhoeck \& Ruprecht, Göttingen 1963, 252. En contra Robert H. Gundry, Mark. A Commentary on His Apology for the Cross, Eerdmans, Grand Rapids, Michigan 1993, 698 .

65 Alan H. Cadwallader, In Go(l)d We Trust: Literary and Economic Currency Exchange in the Debate over Caesar's Coin (Mark 12:13-17), en: Biblical Interpretation 14 (2006) 486-507, aplica una estrategia de lectura marxista de la inscripción para subvertir el poder político-religioso.

66 Cf. J. Gnilka, El Evangelio 179, lo que le lleva a suponer que la localización de la perícopa en el templo es errónea e históricamente improbable. Robert H. Gundry, Mark 698 no considera que ello constituyera un problema moral para los judíos, pues estarían habituados al uso de esa moneda. 
el templo de Jerusalén. Al margen de esta indicación indirecta, sin embargo, la parte narrativa de la perícopa no contiene ninguna indicación temporal o local. Ello implica que los estudiosos se hayan cuestionado la historicidad del relato. La cuestión precisa es si Mc 12,13-17 y sus paralelos proporcionan información histórica sobre la fiscalidad en Judea y sobre la actitud de Jesús ante dicha fiscalidad ${ }^{67}$. Para abordar estas cuestiones, se debe constatar si el redactor trasmitió fielmente su tradición o si la modificó por motivos personales o por necesidades de la comunidad. De ser así, habría que reconstruir el contexto narrativo del incidente dentro de la comunidad marcana.

\subsection{La mano redaccional de Marcos}

La tradición aparece en los tres evangelios sinópticos. Dado el material común en las tres versiones sinópticas de la tradición y sus respectivos contextos, los especialistas han visto una dependencia literaria entre ellos $^{68}$. Mc trasmitiría la tradición más antigua, mientras que las versiones

67 Jesús tiene una visión poco clara sobre el pago del medio shequel como impuesto para el templo (Mt 17,25), sin embargo pide a Pedro que pague el impuesto religioso (Mt 17,27). Es difícil pensar que Jesús enseñara que esos hijos libres tuvieran que pagar el impuesto al emperador. Al margen de la respuesta inteligente en Mc 12,17, es posible que enseñara a sus discípulos que en el reino de Dios no se pagarían más impuestos al emperador, lo cual sería una explicación contra Jesús en Lc 23,2.

68 Existe una cuarta versión de la perícopa trasmitida en el Papiro Egerton 2, encontrado en 1934 y cuya datación se suele situar en torno al año 150 d.C. La traducción del texto es la siguiente: "Y presentándose ante Él en plan indagatorio, le tentaban diciendo: 'Maestro Jesús, sabemos que eres venido de Dios, pues tus obras están de acuerdo con el testimonio de los profetas. Dinos, pues: ¿Es lícito dar a los reyes lo que corresponde a (su) autoridad? ¿Se lo damos o no?'. Mas Jesús, indignado al conocer su pensamiento, les dijo: ¿Por qué me llamáis maestro con los labios, si no escucháis lo que os digo? Bien profetizó de vosotros Isaías, diciendo: Este pueblo me honra con los labios, mas su corazón está lejos de mí. En vano me reverencian........ mandatos" (Egerton Pap. 2, Fragm. II [recto], traducción tomada de Aurelio de Santos Otero, Los Evangelio Apócrifos. Edición crítica y bilingüe, Reimpresión, BAC, Madrid 2002, 95. El fragmento recoge únicamente conflictos y disputas de Jesús, prescindiendo de toda ambientación histórica. Esta variante viene considerada generalmente en los comentarios como secundaria, proveniente de elementos joánicos y sinópticos, cf. Joseph A. Fitzmyer, El Evangelio según Lucas: IV. Traducción y comentarios. Capítulos 18,15-24,53, Cristiandad, Madrid 2005, 162-163; Craig A. Evans, Mark 8:27-16:20 (WBC 34b), Thomas Nelson Publishers, Nashville 2001, 243. Existen otras dos variantes abreviadas en Justino, 1 Apol 17,2 y ThomEv 100: "Mostraron a Jesús una (moneda de) oro y le dijeron: Los agentes del César nos reclaman los impuestos. Él les dijo: Dad lo de César a César. Da lo de Dios a Dios y lo que es mío, dádmelo vosotros". Cf. E. Cuvillier, Marc, Justin, Thomas et les autres. Variations autour de la péricope du denier à César, en: ETR 67 (1992) 329-344; Joel Marcus, Mark 818-821. 
de Lc y Mt serían secundarias y derivarían de Mc 12,13-1769. Por tanto, para ver la naturaleza y el contenido de la tradición sobre el pago de los impuestos al emperador tenemos que centrarnos en la versión de Mc.

La mayor parte de los comentarios que analizan la historia de la tradición de la perícopa consideran el relato no simplemente pre-marcano en su origen, sino que su estado actual de la perícopa debe pocos retoques a la actividad redaccional de Mc. Con excepción hecha de los vv. $13^{70}$ y $17 \mathrm{~b}$, el resto de la perícopa es una reproducción fiel de una unidad tradicional de material que ya estaba fijada en su forma actual mucho antes que Mc la recibiera. Apoyándose en la opinión autoritativa de Rudolf Bultmann ${ }^{71}$, los exegetas suelen aceptar los argumentos de la crítica formal para afirmar que el pasaje de la moneda y, en concreto, el dicho de Mc 12,17 / / Mt 20,22 / / Lc 20,25, es una tradición auténtica de Jesús. Davies y Allison resumen este consenso con las siguientes palabras: "Los eruditos se han abstenido generalmente de hipotéticas historias de la tradición para Mc 12,13-17 par. Al margen del v. 13, existen pocos signos redaccionales atribuibles a Mc y la mayoría ha encontrado en esta escena estilizada una reminiscencia histórica auténtica"72. Esta posición es reafirmada por las conclusiones obtenidas de tres consideraciones interrelacionadas. En primer lugar, el análisis de la historia de las formas muestra que el texto es un diálogo de disputa cuya forma es clásica, concluyendo con una sentencia de Jesús y precedida de una disputa que sirve de "marco" al logion, marco que indica la ocasión y la situación del diálogo. En segundo lugar, la sentencia apodíctica de Jesús (v. 17) es sin duda tradicional, ya que no podía circular al mar-

69 Para la cantidad de material común, los acuerdos verbales y las respectivas contextualizaciones de las tres versiones cf. C.H. Giblin, The Things of God in the Question concerning Tribute to Caesar (Lk. 20:25; Mk. 12:17; Mt. 22:21), CBQ 33 (1971) 515-516. Para la dependencia literaria de Mt y Lc respecto a Mc cf. Jeffrey B. Gibson, The Temptations of Jesus in the Early Christianity (JSNTS 112), Sheffield Academic Press, Sheffield 1995, 289s., n. 4.

70 Según J. Gnilka, El evangelio 176, Mc dio forma a la totalidad del v. 13, y la entrada sonaba probablemente de la misma manera que 12,18.28: "Y vienen a él fariseos (¿herodianos?) para pillarle en alguna palabra...".

71 Según Rudolf Bultmann, Historia de la tradición sinóptica, Sígueme, Salamanca 2000,85 , el v. 17 es un apotegma de concepción uniforme y estructura excelente. No cree que exista razón para ver aquí una composición de la comunidad. No obstante, en la página 107 considera que este pasaje debió formarse ya en la tradición oral, al que la comunidad dio forma y que esta no tiene por qué reflejar sin más sucesos históricos, sino situaciones de la comunidad de los discípulos. La situación vital de los litigios habrá que buscarla en las discusiones que la comunidad mantenía con sus adversarios. A favor de la historicidad del relato durante la estancia de Jesús en el templo cf. Craig A. Evans, Mark 244.

72 W. D. Davies - Dale C. Allison, A Critical and exegetical Commentary on the Gospel according to Saint Matthew. Vol. III, T.T. Clark, Edinburgh 1997, 211. 
gen de una situación y de un motivo por el que se pronunció. Y finalmente, el relato está correctamente estructurado, con los elementos mínimos esenciales para conducir la historia a su clímax.

No obstante, han surgido estudiosos que han puesto en tela de juicio este consenso o han matizado mucho el material tradicional, descubriendo cada vez más elementos provenientes de la mano redaccional del evangelista. Ya Wolfgang Weiss rechazó esta aquiescencia sobre la historicidad de una parte del relato, al igual que John Meier, quien afirma: "Mc 3,6 y 12,13, tal y como están en el texto de Marcos, no nos dicen nada fiable sobre incidentes concretos en la vida del Jesús histórico"73. El preámbulo del texto de Mc (vv. 13-14) es muy prolijo y amplio, tal y como Bruce ${ }^{74}$ constató, aunque según este autor ello no es signo de un desarrollo secundario posterior, dado que se adecua al contexto. En contra, J. Gnilka considera el v. 14 sobrecargado, por lo que es probable que Mc lo haya incluido, especialmente la frase causal, "porque no miras a la persona del hombre sino que enseñas con verdad el camino de Dios", aunque es difícil decidir con seguridad $^{75}$. Otras peculiaridades redaccionales han sido constatadas por Joel Marcus 76 en su magnífico comentario sobre el segundo evangelio: el lenguaje sobre la percepción (conocer, mirar, ver), el uso de expresiones dobles, incluyendo una negativa doble, los temas de enseñanza, el camino de Dios/del Señor y la prueba a Jesús de parte de los fariseos. Estos rasgos, bien pudieran provenir de la mano redaccional del evangelista, lo cual es especialmente evidente en el v. 13, donde habría añadido el término de los herodianos a los interlocutores para formar una inclusión con Mc 3,6. La labor redaccional también se constata en la conclusión de la perícopa, ya que el asombro producido por la respuesta de Jesús responde perfectamente al modelo típico marcano.

Por su parte, Jeffrey B. Gibson va mucho más allá en su valoración sobre la labor editorial77. Este autor considera que el logion de Jesús es tradicional y nunca circuló independientemente de algún marco narrativo o introducción. No obstante, es improbable que el material con el que Mc introduce y enmarca el dicho de Jesús sea tradicional y original al logion. Y

73 J. Meier, Marginal Jew, 3:565; Wolfgang Weiss, "Eine neue Lehre in Vollmacht": die Streit- und Schulgespräche des Markus-Evangeliums, Walter de Gruyter, Berlin 1989, 202-34.

${ }^{4}$ F.F. Bruce, Render to Caesar, en: E. Bammel - C.F.D. Moule (eds.), Jesus and the Politics of His Day, Cambridge University Press, Cambridge 1984, 257.

75 J. Gnilka, El evangelio 176.

76 Joel Marcus, Mark 8-16 818.822.

77 Jeffrey B. Gibson, The Temptations 294s. 
ello por varios motivos. La construcción triádica ${ }^{78}$ del diálogo es atípica de la forma y estructura de estos relatos de disputa, por lo que el relato marcano es tardío en origen y sería producto de la actividad redaccional. La redundancia y verbosidad de las alabanzas de los interlocutores hacia Jesús, especialmente cuando contrasta con el laconismo precedente y posterior y entre lo pretendido y la realidad, es un signo claro de la labor redaccional de autores conocedores de la retórica, pero difícilmente pensable en un autor de literatura popular (Kleinliteratur). En tercer lugar, argumenta que la historia de la tradición se conserva mejor en el logion 100 del Ev. Tomás (sin el añadido gnóstico de "dadme a mí lo que es mío"), ya que es mucho más breve y su compilador no tendría razones para omitir algunas expresiones de Mc 12,14 (a pesar de que muchos autores consideren ese logion una conflación tardía de Mc). El Ev. de Tomás conserva una versión del relato que es paralela e independiente de la versión de $\mathrm{Mc}$ e, incluso, esta chreia constituye la fons et origo de la tradición sinóptica. Por consiguiente, la versión de Mc no representa una reproducción fiel e inalterada del material primitivo tradicional y, en segundo lugar, gran parte del material en Mc 12,13-17, aunque basado en una chreia primitiva, es una construcción editorial creada en el estadio literario de la tradición sinóptica.

El evangelista Mc sería, por consiguiente, el responsable de esa versión de la tradición tal, y como muestran algunos indicadores: a) la estructura triádica; b) el relato abunda en exceso de "dualidad" temática y estilística, típicamente redaccionales (doble dialéctica de pregunta y respuesta; repeticiones en vv. 14-15a; dualismo en los interlocutores; una correspondencia entre mandato y cumplimiento vv 15b-16). Así mismo, también se detectan otros rasgos estilísticos de la narración producto de la huella redaccional 79 y un vocabulario típicamente marcano: maestro, enseñar, verdadero/verdad, saber, tentar, traer, mirar... Por tanto, la estructura y la mayor parte del material provendrían del evangelista.

Gibson concluye afirmando que el análisis de la historia de la tradición del pasaje ha constatado que la versión marcana de la tradición de Jesús referente al impuesto al emperador es una expansión secundaria realizada por un evangelista del relato pre-marcano, la cual se preserva mejor en el logion 100 del Ev. Tom. Mc habría alterado, al menos, de dos formas

78 J.D. Crossan, Mark 12:13-17, en: Int 37 (1987) 397.

79 Cf. Jeffrey B. Gibson, The Temptations 298s: $\tau$, usado como una exclamación (v.

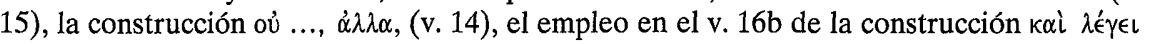
aủtoîs para introducir un logion de Jesús. 
la versión que recibió. En primer lugar, transformó la forma de la versión original (chreia) en un relato de disputa o en un diálogo de controversia no unitario. En segundo lugar, modificó significativamente la introducción contextual de la tradición original mediante un cambio de interlocutores: en lugar de ser sus compatriotas o compañeros quienes planteaban la cuestión a Jesús, serán sus oponentes o enemigos. Asimismo, añadió el contexto, situando el relato en un lugar concreto (en Jerusalén, en la última semana de la vida de Jesús) y relacionando lo que sucede y las pretensiones de acabar con el maestro bueno con la línea del complot que ya había aparecido en el inicio del evangelio (el deseo de las autoridades religiosas judías de acabar con Jesús, Mc 11,18; Mc 3,16). De la pluma marcana provendría además la formulación de la cuestión sobre la legitimidad del impuesto, ya

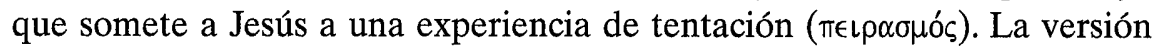
de la tradición más antigua ya contenía la cuestión del pago de los impuestos, sin embargo Mc fue innovador en la forma y en el contenido del material, pero al retomar el tema, "el segundo evangelista actuó de manera conservadora y permaneció tradicionalista" 80 .

$\mathrm{Al}$ margen de la valoración concreta que merezcan varias de las afirmaciones de Gibson, como es la prioridad del logion 100 del ev. de Tomás, considero que el evangelista también introdujo en su relato los vocablos "denario" y "herodianos", términos que nos ayudarán a descubrir el contexto narrativo del incidente dentro de la comunidad de Mc.

\section{3. ¿El denario ante Jesús?}

Las formulaciones de Mc 12,15c y Lc 20,24a no implican la existencia de una relación directa entre el denario y el impuesto debido al César. Esta relación es establecida por la versión de Mt, tanto en la petición de Jesús como en la respuesta de sus interlocutores $(22,19)$ : "Muéstrame la moneda del tributo. Y ellos le trajeron un denario". El denario es, pues, la "moneda

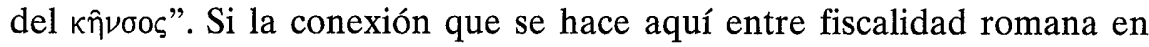
Judea y el denario es una verdadera reminiscencia de las condiciones tributarias de Judea en tiempos de los prefectos romanos, el pasaje de Mt constituiría la única evidencia directa que tenemos para afirmar que Roma recaudaba impuestos en metálico y, concretamente, en denarios. Al margen de que su exacción se realizara o no en denarios, los tres pasajes de los

80 Jeffrey B. Gibson, The Temptations 317. 
evangelios sugieren que la monetización romana era común en Judea en la época de Jesús. Veamos si realmente fue así.

El emperador Augusto organizó y sistematizó la acuñación de moneda en el año 19 a.C. mediante tres tipos de metales: monedas de oro, plata y bronce puro (o una aleación de cobre y cinc). El aureus de oro, el denario de plata (25 denarios $=$ un aureus) y el as de cobre (16 asses = un denario) constituían las principales monedas en circulación. Como moneda habitual y medida de contar permaneció el sestertius, equivalente a 4 asses ${ }^{81}$. La cantidad de moneda acuñada variaba según la política imperial ${ }^{82}$ y procedía en su mayor parte de dos centros de acuñación, aunque existían otras cecas de segundo rango. La casa de la moneda de Lyon (Lugdunum) produjo la mayor parte de las monedas imperiales de oro y plata desde el 15 a.C. hasta que Nerón trasladó su ubicación a Roma. Por su parte, las monedas de bronce se acuñaban en las provincias. Al margen de las monedas imperiales oficiales que circulaban en todo el imperio en mayor o menor grado, existían también los tetradacmas, didramas y dracmas de plata acuñados por varias ciudades griegas, y en Palestina ${ }^{83}$ circulaban frecuentemente monedas de plata acuñadas en Tiro (Shequel de Tiro), además de las monedas locales de bronce troqueladas por las autoridades competentes.

En Judea, en tiempos de Jesús, el procurador tenía la potestad de emitir moneda ${ }^{84}$. Los estudiosos de Nuevo Testamento han dedicado especial atención a las piezas acuñadas por Poncio Pilato ${ }^{85}$, no por su valor monetario, sino por su proximidad temporal, geográfica y humana a Jesús. Este procurador diseñó y acuñó en Jerusalén monedas en los años 29, 30 y 31, las cuales puso en circulación y Jesús muy probablemente tuvo en sus

81 Cf. T.E. Schmidt, Taxes, en: Joel B. Green - Scot McKnight - I. Howard Marshall (eds.), Dictionary of Jesus and the Gospels, IVP, Downers Grove, Ill. - Leicester 1992, 804-807.

82 Richard Duncan-Jones, Money and Government in the Roman Empire, Cambridge University Press, Cambridge 1994; Kenneth Harl, Coinage in the Roman Economy, 300 B.C. to A.D. 700, Johns Hopkins University Press, Baltimore 1996.

83 Para la acuñación de las monedas en ciudades de Palestina: Alla Kushnir-Stein, City Eras on Palestinian Coinage, en: Christopher Howgego - Volker Heuchert - Andrew Burnett (eds.), Coinage and Identity in the Roman Provinces, Oxford University Press, Oxford 2005, 157-161.

84 A. Kushnir-Stein, Editor's Note. New INR Classification for Early Roman Governors of Judea, en: INR 2 (2007) 3-4.

85 H.K. Bond, The Coins of Pontius Pilate: Part of an Attempt to Provoke the People or to Integrate them into the Empire?, en: JSJ 27 (1996) 241-262; cf. el artículo al respecto de Jean-Philippe Fontanille, The Coins of Pontius Pilate, en internet (visto 19-122011) http://www.numismalink.com/fontanille1.html; cf. monedas emitidas por Pilato, http://www.wildwinds.com/coins/greece/judaea/pontius_pilate/t.html 
manos, o al menos tiró por los suelos al volcar las mesas de los cambistas. Se trata de monedas romanas con inscripciones en griego: TIBEPIOY KAICAPOC en todas las tres monedas acuñadas; IOYLIA KAICAROC añadida a la moneda del año 29 d.C. La iconografía decorativa era generalmente la corona de laurel, símbolo de poder y victoria, o tres espigas de cebada. Más llamativas son, sin embargo, las representaciones iconográficas de los símbolos del lituus y simpulum, elementos romanos con connotaciones del culto imperial ${ }^{86}$. El simpulum es un utensilio empleado por los sacerdotes romanos durante sus ceremonias religiosas, mientras que el lituus hace referencia a un cayado de madera que los augures mantenían en su mano derecha levantada hacia los cielos cuando invocaban a los dioses o hacían sus predicciones. Estos motivos decorativos fueron elegidos en un período creciente de procesos judiciales tras la restauración de la lex maiestate por Tiberio en el año 15 d.C., por lo que Pilato ${ }^{87}$ deseaba subrayar su lealtad al emperador mediante la devoción a Augusto 88 .

No obstante, no nos centraremos en las monedas de bronce acuñadas por Pilato, sino en el denario de plata que presupone el relato de Mc. Es obvio que la moneda que mejor se adapta a los requisitos de la narrativa es el denario de plata del emperador Tiberio César, tal y como Hart ${ }^{89}$ sugirió. Durante el reinado de Tiberio se troquelaron dos tipos de denarios; el primero de ellos dejó de circular al poco tiempo de ser emitido en el 15/16

86 Joan E. Taylor, Pontius Pilate and the Imperial Cult in Roman Judaea, en: NTS 52 (2006) 555-582, mientras que Poncio Pilato es visto a menudo como agnóstico, en términos modernos, las pruebas materiales de sus monedas y la inscripción de Cesarea dejan entrever que estamos ante un prefecto decidido a promover una forma de religión romana en Judea, el culto al emperador Tiberio en Jerusalén.

${ }^{87}$ Helen K. Bond, Pontius Pilate in History and Interpretation (SNTSMS 100), Cambridge University Press; Cambridge 2004, 19-22; Warren Carter, Pontius Pilate: Portraits of a Roman governor, A Michael Glazier Book, Liturgical Press, Collegeville, Minnesota 2003, 35-54 (los gobernadores y el sistema imperial romano).

88 D.M. Hoffeditz, Divus of Augustus: The Influence of the Trials of Maiestas upon Pontius Pilate's Coins, en: INR 1 (2006) 87-96. El autor sugiere que ambos motivos iconográficos representan la imagen del emperador Augusto. Rechazando las nociones tradicionales de que el empleo de estos símbolos provenía del anti-semitismo o de la incompetencia de Pilatos, el artículo propone que los motivos eran resultado del temor de Pilato a aparecer desleal ante Tiberio. Apoyo para esta teoría se encuentra en el uso de este tipo de monedas en otros lugares del Imperio Romano y en los acontecimientos contemporáneos en Roma, en particular la invocación o juramento por la ley de traición (maiestas) en 27 d.C.

${ }^{89} \mathrm{H}$. St. J. Hart, The Coin of "Render unto Caesar..." (A Note on Some Aspects of Mark 12:13-17; Matt. 22:15-22; Luke 20,20-26), en: E. Bammel - C.F.D. Moule (eds.), Jesus and the Politics of His Day, Cambridge University Press, Cambridge 1984, 241-248, aquí 243. Las acuñaciones imperiales de Tiberio se encuentran elencadas en el gran catálogo de Mattingly. Todos sus denarios se atribuyen a la ceca de Lugdunum en la Galia. 
d.C., mientras que el número de monedas acuñadas del segundo tipo fue muy elevado con la intención de que circulara en gran parte del imperio. Este fue considerado como el denario estándar de Tiberio ${ }^{90}$. La imagen y la inscripción, tan intencionadamente señalada en el diálogo, son de gran interés. Así, por regla general, el anverso era troquelado con la imagen del emperador reinante (o de un predecesor que hubiera sido divinizado tras la apoteosis) y una inscripción que contenía sus títulos honoríficos, incluyendo su relación con un emperador deificado. En el denario de Tiberio aparece en el anverso la cabeza laureada de Tiberio, con la leyenda TI(berius) CAESAR DIVI AUG(usti) F(ilius) AUGUSTUS (Tiberio César hijo del deificado Augusto, [él mismo] Augusto). Mayor variedad iconográfica se exhibía en el reverso, en el que aparecían con frecuencia algunos miembros de la familia imperial ${ }^{91}$. En este caso, el reverso proseguía con una figura femenina sentada, probablemente representando a Livia como Pax (personificación de la paz en el Imperio) junto con las palabras PONTIF(ex) MAXIM(us) (= Sumo Sacerdote). Este denario es típico de las monedas imperiales de la época. Hart es consciente de que la moneda en el relato de Mc pudiera tratarse también de un denario de Augusto, que todavía se encontraban en circulación ${ }^{92}$. Si fuera éste el caso, mostraría la efigie laureada o el busto del emperador junto con la inscripción CAESAR AUGUSTUS DIVI F PATER PATRIAE, y en el reverso una imagen de los príncipes imperiales ${ }^{93}$, Gayo y Lucio, cada uno con una lanza en la mano, una estrella, indicando la sanción divina, y una imagen del stipulum y del litius junto con la inscripción PRINCIPES IUVENTUTIS. Incluso podría tratarse de una moneda de Alejandría (un billón tetra-

90 La identificación estandarizada, ampliamente aceptada, se remonta más allá de la primera edición (1864) de Frederic W. Madden, History of Jewish Coinage and of Money in the Old and New Testament, B. Quaritch, London, 1864, reprinted, Ktav, New York, 1967), p. 247.

91 Cf. H.A. Seaby - Robert Loosley, Roman Silver Coins. Vol. II: Tiberius to Commodus, Seaby, London 1979³, 1; A. Burnett - M. Amandry - P. Pau Ripolles, Roman Provincial Coinage I: From the death of Caesar to the death of Vitellius (44 BC-AD 69), London/Paris 1992, 63; C. H. V. Sutherland, The Roman Imperial Coinage I2, London 1984; Richard J. Plant. Roman Silver Coins - A Price Guide, Rographic 2nd Edition (C) MMVI, p. 37

92 H. St.J. Hart, "The Coin" 244.

93 RIC I 207, cf. H. Shore, The Real Tribute Penny, en: Australian Coin Review 377 (December 1995) p. 37. También se ha propuesto como la moneda del tributo el tetradracma de Antioquia con Tiberio en el anverso y Augusto en el reverso ( $R P C$ 4161) cf. P.E. Lewis, The Actual Tribute Penny, en: JNAA 10 (1999) 1-13 y Peter E. Lewis - Ron-Bolding, The pocket guide to Saint Paul. Coins encountered by the apostle on his travels, Wakefield Press, Kent Town 2002, 19-20.235. 
dracma), la cual equivalía casi a un denario, aunque para esa identificación existe el problema del aislamiento monetario de Egipto ${ }^{94}$.

Sin embargo, no todas las investigaciones numismáticas confirman el resultado de Hart. Así, los estudios de J.-B. Giard sobre la monetización procedente de Lugdunum muestran que, de los dos hallazgos de monedas troqueladas en Lyon (en este caso para Britannia), cuatro quintas partes de los denarios acuñados durante el gobierno de Tiberio pertenecen a los últimos seis o siete años de su reinado. Sin embargo, el modelo y las estadísticas son diferentes para los aurei, que alcanzaron su punto álgido de acuñación en los años 14-16 d.C con el 37\% del total de moneda emitida durante su reinado ${ }^{95}$.

Además, la identificación del "denario" del pasaje sinóptico con las monedas de Tibèrio se sostiene desde la conclusión: se supone lo que los textos suponen que deben demostrar, a saber, que el denario imperial era común y corriente en Palestina y se requería ese tipo de moneda para la tributación romana. Como Leo Kadman constató: "estas preguntas y respuestas [de la perícopa de Marcos] fueron solo posibles cuando Jesús pudiera asumir que las piezas de plata encontradas en los bolsos de los hombres de a pie eran romanas o monedas imperiales romanas, con la imagen e inscripción del emperador"96. De forma semejante, los estudios de Frederic Madden ${ }^{97}$ y Leo Kadman, basados fundamentalmente en fuentes literarias (Biblia hebrea, NT, y literatura clásica, rabínica y cristiana) llegaban a la misma conclusión. La mención evangélica del denario les proporcionaba una prueba inestimable para afirmar que el denario era la moneda cotidiana de plata en los bolsillos judíos durante la segunda y tercera década del siglo primero d.C. Así, Kadman considera que las monedas de Tiro no circulaban habitualmente en Palestina, ya que las monedas de plata en circulación eran casi exclusivamente romanas o imperiales romanas. Tanto los Evangelios como Flavio Josefo hacen referencia al uso de esta mone-

94 H. St.J. Hart, "Coin" 247: "billion tetradrachm of Alexandria: It is perhaps the best candidate, other than a denarius, for the "identification"".

$95 \mathrm{Cf}$. el apéndice dedicado a la cronología de la acuñación de las monedas de Tiberio en Richard Duncan-Jones, Money and Government 250s. cf. J.-B. Giard, Le monnayage de Vatelier de Lyon, 43 av. J.-C. a 41 ap. J.-C. (Wetteren) (1985).

${ }^{96}$ Leo Kadman, Temple Dues and Currency in Ancient Palestine in the Light of Recent Discovered Coin-Hoards, en: Atti del congresso internazionale di numismatica, Roma, 1961, vol. 2, Istituto Italiano di Numismatica, Roma 1965, 70. Hart, "Coin" 241, n. 2 cita y aprueba el estudio de Kadman; Leo Kadman, Temple Dues and Currency in Ancient Palestine in the Light of Recent Discovered Coin-Hoards, en: Israel Numismatic Bulletin 1 (1962) 10.

${ }^{97}$ Frederic W. Madden, History of Jewish Coinage. 
da ${ }^{98}$. En contra de esta argumentación basada en las fuentes literarias, se debe señalar que estos estudiosos no tienen en consideración el auditorio para el que escriben los evangelistas o Flavio Josefo: dar cifras monetarias en una moneda desconocida para un público ajeno al valor monetario referido, dificulta el discurso y la valoración de la cuantía económica aducida. Por eso hacemos intuitivamente un "cambio" monetario adoptando la divisa del interlocutor, de tal forma que el mensaje del discurso sea comprensible.

Ya en 1945, Spencer Kennard cuestionó la propuesta de Hart basándose en los hallazgos numismáticos. Sus estudios le llevaron a la conclusión de que las hordas de monedas de esa época encontradas en Siria parecían indicar todo lo contrario: "Si se compara la relación porcentual de las monedas romanas de plata con los amplios hallazgos de monedas de bronce, se podría concluir que el denario no jugó un papel relevante en la vida de los judíos contemporáneos de Jesús"99.

Ante esta crítica, Hart era consciente de que se habían encontrado pocos denarios imperiales en Palestina. No obstante, el hallazgo posterior de la horda de Isfiya lo interpretó como una corroboración de los datos literarios del NT y de Josefo, por lo que concluyó que el denario romano desempeñó un papel importante en el sistema monetario de Palestina en tiempo de Jesús. Este hallazgo consta de unas 4.500 monedas: 3.400 sequels de Tiro ${ }^{100}, 1.000$ medios-sequels de Tiro y 160 denarios romanos, de los cuales 30 pertenecen a la época de Tiberio. La valoración de esta horda monetaria realizada por otros estudiosos ${ }^{101}$, sin embargo, contradice lo propuesto por Hart. Incluso las monedas encontradas en Qumran y la mayor parte de las monedas de la Alta Galilea y en Séforis confirman que la moneda más común en tiempos de Jesús era el sequel de Tiro ${ }^{102}$.

98 Flavio Josefo y el último redactor de Mc escriben para un público romano. La experiencia personal y general muestra que cuando un español vivía en Alemania y relataba a un alemán, desconocedor del sistema monetario español, aspectos de la carestía de la vida de nuestro país, intuitivamente hacíamos el "cambio" monetario de la peseta al marco alemán, de tal forma que el interlocutor se hiciera una idea más precisa, es decir, adaptábamos la moneda del país de acogida incluso aunque estuviéramos hablando de nuestro país de origen.

99 Spencer J. Kennard, Jr., Syrian Coin Hoards and the Tribute Question, en: AThR 27 (1945) 248-52; cita de la p. 252.

100 Cecilia Meir, Tyrian Sheqels from the 'Isfiya Hoard, Part Two, en: Israel Numismatic Research 5 (2010) 143-150.

101 Meshorer también observó que "estos denarios de Tiberio son bastante raros en esta parte del mundo", y llamó el tesoro de Isfiya "el sólo buen ejemplo de un hallazgo incluyendo esas monedas".

102 Cf. Danny Syon, Tyre and Gamla. A Study of the Monetary Influence of Southern Phoenicia on Galilee and the Golan in the Hellenistic and Roman Periods, PhD diss., 
Por su parte, Donald T. Ariel103 se aparta de la metodología de apoyarse exclusivamente en las fuentes literarias (cf. Madden y Kadman) y llega a conclusiones históricas sobre la monetización sólo cuando las pruebas numismáticas las garantizan. Su estudio proporciona una recopilación sistemática de los detalles y la localización de los denarios imperiales. Teniendo en cuenta las monedas que han salido a la superficie en las excavaciones y hallazgos numismáticos en Jerusalén ${ }^{104}$, Ariel ha identificado siete monedas romanas con fechas anteriores al año 67/68 d.C. De las siete monedas, una ( $\mathrm{n}^{\circ}$ 54) es un denario de plata de Augusto (datación 2 a.C.11 d.C.), otra ( $\mathrm{n}^{\circ}$ 61) es un aureus de oro de tiempos de Tiberio (14-37 d.C.) y sólo uno $\left(\mathrm{n}^{\circ} 60\right)$ es un denario de plata del reinado de Tiberio, que fue acuñado en Roma. Otros dos hechos emergen del estudio de Ariel. En primer lugar, los tetradracmas y los denarios romanos de plata aparecen de forma significativa en Jerusalén sólo después de 69 d.C., especialmente tras el reinado de Vespasiano. En segundo lugar, en el período anterior al año 69 d.C., hubo, por el contrario, una preponderancia continua de monedas de plata de Tiro. Este cuadro es confirmado por los hallazgos de monedas de plata en Qumran y sus alrededores. Ariel concluye de su análisis numismático que los denarios romanos no se convirtieron en moneda corriente en Jerusalén hasta después del año 70 d.C., aunque es verdad que algunas monedas romanas circulaban anteriormente en la región. Sin embargo, el shequel de Tiro constituyó la moneda de plata por excelencia de la región durante todo este periodo hasta la revuelta judía, dado que ni los asmoneos ni los herodianos parecen haber acuñado monedas de plata ${ }^{105}$. De forma semejante, los autores del $\mathrm{RIC}^{106}$ afirman que los denarios romanos no se

Hebrew University, Jerusalem. 2004, 65-75. Consultada (25.01.2012):

http://antiquities.academia.edu/DannySyon/Papers/323206/Tyre_and_Gamla_A_Stu dy_In_the_Monetary_Inlfluence_of_Southern_Phoenicia_on_Galilee_and_the_Golan_In_ the_Hellenistic_and_Roman_Periods

103 Donald T. Ariel, A Survey of Coin Finds in Jerusalem (Until the End of Byzantine Period), en: Liber Annuus Studii Biblici Franciscani 32 (1982) 273-326.

104 H. Gitler, A Comparative Study of Numismatic Evidence from Excavations in Jerusalem, en: $L A 46$ (1996) 317-362, no recoge en su estudio comparativo las monedas imperiales, aunque sí las de los procuradores.

105 Morten Hørning Jensen, Herod Antipas 191. Su estudio sobre la monetización de Herodes Antipas llega también a la misma conclusión, basado en el estudio numismático de Danny Syon: en Gamla, sólo el 4,8 \% de las monedas son herodianas o de la administración romana; la mayor parte de las monedas proceden de la dinastía asmonea. "Only 39 Roman imperial coins are recorded from the early Roman period (Syon 2004, 249) restricting the coins in circulation in Galilee in this period, to mainly Hasmonean and thereafter Herodian and Roman coins" (p. 215).

106 A. Burnett - M. Amandry - P. Pau Ripolles, Roman Provincial Coinage 12. 
acuñaban ni circulaban en Siria, siendo los tetradracmas de Antioquia o los shequels de Tiro las monedas de plata en circulación en esa provincia romana. Esta misma visión es defendida por Morten Hørning Jensen en su estudio dedicado a Galilea en tiempos de Herodes Antipas. Su reinado no significó un incremento de la producción y circulación de monedas pequeñas de cambio. Los negocios se realizaban de forma corriente mediante monedas asmoneas, y solamente en un periodo más tardío, periodo romano medio, experimentó Galilea un aumento de la circulación monetaria incluyendo monedas imperiales romanas.

La segunda cuestión importante respecto al denario es si los impuestos se debían abonar en metálico y, específicamente, en denarios. Para el Imperio Romano en general, la cuestión de las formas de pago de los impuestos directos, en especie o en efectivo, plantea complejos problemas. Por lo que se refiere al tributum soli, las pruebas disponibles no permiten resolver completamente la cuestión de si éste se abonaba sólo en espe$\mathrm{cie}^{107}$. Por otra parte, la propuesta de Jones ${ }^{108}$, según la cual los censos provinciales de Augusto introdujeron impuestos de la tierra mediante prorrateo pagados en efectivo, no es compatible con las evidencias. Es imposible determinar con precisión el porcentaje de ingresos fiscales que Roma recaudaba en sus provincias en metálico y qué repercusiones habría tenido esto sobre el Imperio. Aunque el Imperio Romano en cierta medida estaba monetizado, su base económica permaneció siendo, en su mayor parte, agrícola.

Así Babatha ${ }^{109}$ pagada parte de sus impuestos en productos (papiro Yadin 16.19-32) ${ }^{110}$, mientras el "impuesto de la corona" venía abonado en

107 Para apoyar el hecho de que Roma recaudaba impuestos en denarios se suele aducir la inscripción bilingüe de Palmira OGIS 629 (136/7 d.C.), cf. Bruce, "Render to Caesar" 258. No obstante, este decreto de la ciudad se refiere a los impuestos arancelarios y portuarios del transporte de mercancías; se trata no de impuestos estatales romanos, sino de tasas sobre productos recaudados para su administración interna.

108 A. H. M. Jones, The Roman Economy, en: P.A. Brunt (ed.) Studies in Ancient Economic and Administrative History, Blackwell, Oxford 1974, 161-166; Richard DuncanJones, Structure and Scale in the Roman Economy, Cambridge University Press, Cambridge 1990, 187-198: "The contention that a general change to levying taxes in money took place in the time of Caesar and Augustus can be seen to rest on very little. Evidence for payment of taxes in kind continues under the Principate, both in Egypt and in other provinces" (p. 197). De la misma opinion es Ze'ev Safrai, The Economy of the Roman Palestine, Routledge, London - New York 1994, 198.

109 Los documentos fueron publicados por Naphtali Lewis en, Yigael Yadin - Jonas C. Greenfield (eds.), Judean Desert Studies: The Documents from the Bar Kokhba Period in the Cave of Letters, Greek Papyri, Aramaic and Nabataean Signatures and Subscriptions, Israel Exploration Society, Hebrew University of Jerusalem, Jerusalem 1989, pp. 37, 38, 66, 95, 98 (P. Yadin 5, 16, 21 and 22); Hannah M. Cotton, Rent or Tax Receipt from 
metálico $(16,20,27,32)$. El relato de Flavio Josefo sobre la recaudación del tributo en la provincia de Judea parece sugerir que también se hacía el pago en efectivo. La conclusión de que, en general, se efectuaba el pago en especie puede apoyarse en la presencia de los silos de "grano imperial" en las aldeas de la Alta Galilea. El tributo así recaudado en productos, se podía convertir en dinero efectivo, como indica la acusación de Flavio Josefo que su rival, Juan de Giscala, quería invertir el grano de esos silos para reparar las murallas de su ciudad natal (Vita 70-73).

Al margen de la dificultad que supondría para los judíos observantes tener dentro del mismo recinto del templo una moneda romana ofensiva a la sensibilidad de los judíos piadosos ${ }^{111}$, también los estudios numismáticos plantean serias dudas acerca de la historicidad del relato de la moneda del denario para el tiempo de Jesús, pues su raro uso haría problemático el pago del tributo con esa moneda. Si añadimos además, que no era obligatorio pagar el tributo en metálico, sino que también se podía realizar en especie, ello nos lleva a concluir con Fabian Udoh que "algunos impuestos, especialmente los peajes y derechos [impuestos indirectos] habrían sido abonados en efectivo. Sin embargo, los denarios imperiales no eran exigidos para la tributación romana y no formaban la base de la moneda de plata en la región. La conexión que se hace en los Evangelios, especialmente en Mt 22,19, entre fiscalidad romana en Judea y el denario no ofrece ninguna información histórica específica sobre fiscalidad en Judea durante la vida de Jesús"112. Por tanto, la mención del "denario" en el relato se debe muy probablemente a la labor redaccional de Marcos o a una labor editorial posterior. A esta misma conclusión ya había llegado anteriormente, aunque por distinto camino, Martin Rist.

La obra de este autor es significativa porque investiga la plausibilidad histórica del supuesto contexto narrativo de Mc. El diálogo sobre el denario, según Rist ${ }^{113}$, no pertenecía a la historia original. Así, mientras que "es

Ma’oza, en: ZPE 100 (1994) 547-557 (P. XÓev/Se Gr.5). Para la localización de los hallazgos, cf. H. Cotton, en Wolfram Weiser - Hannah M. Cotton, "Gebt dem Kaiser, was des Kaisers ist...": Die Geldwährungen der Griechen, Juden, Nabatäer und Römer im syrischnabatäischen Raum unter besonderer Berücksichtigung des Kurses von Sela'/Melaina und Lepton nach der Annexion des Königreiches der Nabatäer durch Rom, en: ZPE 114 (1996) 237 n. 2.

110 Martin Goodman, "Babatha's Story" Review of Y. Yadin, The Documents from the Bar Kokhba Period in the Cave of Letters: Greek Papyri, en: Journal of Roman Studies 81 (1991) 169-175.

111 M. Eugene Boring, Mark 335.

112 Fabian Udoh, To Caesar What Is Caesar's 227s.

113 Martin Rist, Caesar or God (Mark 12:13-17)? A Study in "Formgeschichte", en: The Journal of Religion 16 (1936) 317-331. 
razonable suponer que Jesús fue interrogado, no una vez sino varias veces, sobre la conveniencia de pagar impuestos a Roma, porque este constituía un tema candente entre los judíos de su tiempo", con la introducción de la moneda con la imagen de César en la narrativa, "el énfasis de la perícopa se desplaza desde el problema judío de pagar tributo al César al dilema cristiano de rendirle culto como a un Dios". Rist se aparta de la opinión generalizada de que el contexto narrativo (Sitz im Leben) de la historia tal y como se encuentra hora es la cuestión del pago del tributo a Roma. Veamos su argumentación.

Hay que tener presente que la prohibición judía de las imágenes incluía también a las monedas. En el periodo romano antes del año 70 d.C., bajo el gobierno de la dinastía de Herodes y los prefectos romanos, las monedas de cobre y bronce que se habían troquelado para su circulación en Judea no contenían imágenes, salvo una excepción menor (una moneda herodiana con la imagen de un águila114); del mismo modo, sus inscripciones no eran ofensivas a los sentimientos religiosos de los judíos. Esta concesión hecha por los romanos, equiparable a la exención de participar en el culto imperial, revela la oposición implacable de los religiosos contemporáneos de Jesús a introducir imágenes.

Es cierto que las monedas de tipo griego, sirio y fenicio circulaban en Palestina. Dado que algunas de ellas no mostraban la efigie del emperador, eran menos ofensivas, a pesar de las representaciones de sus dioses y reyes ${ }^{115}$ que el dinero romano. Aún así, era imposible que los judíos piadosos evitaran totalmente el empleo de monedas con la imagen del César en el curso normal de sus negocios. Podemos estar seguros, sin embargo, que su tenencia era breve; conforme a los preceptos rabínicos ${ }^{116}$ en contra de fijar la vista en los ídolos, hay una serie de advertencias para no observar las imágenes de las monedas romanas. Mostrar el denario imperial en el

114 Haría referencia al intento de colocar la imagen del águila sobre la puerta de templo.

115 Martin Goodman, Coinage and Identity: The Jewish Evidence, en: Christopher Howgego - Volker Heuchert - Andrew Burnett (eds.), Coinage and identity in the Roman Provinces, Oxford University Press, Oxford 2005, 163-166, explica el uso de la moneda de Tiro para el pago del impuesto religioso del templo con las siguientes palabras: "Purity of silver content was indeed the only quality of the Tyrian coinage that fitted it for payments of this kind in the Jerusalem shrine, since in respect of its images and slogans, which advertised the holiness of Tyre and the power of its local god Melkart, it was deeply inappropriate" (p. 165).

116 Stefan Schreiner, „... dem Kaiser, was des Kaisers ist“ - Steuern, Zölle und Abgaben in der (früh)rabbinischen Literatur, en: H. Klinkott - S. Kubisch - R. MüllerWollermann (Hrgs.), Geschenke und Steuern, Zölle und Tribute. Antike Abgabenformen in Anspruch und Wirklichkeit, Brill, Leiden - Boston 2007, 159-184. 
templo, centrando la atención en su imagen idólatra e inscripción blasfema, es incompatible con lo que se conoce sobre las leyes judías y los tabúes religiosos de la época. Tampoco se puede afirmar que el incidente ocurriera en otro lugar, p.e. en Galilea, y fuera trasladado al escenario de Jerusalén en la elaboración de evangelio. Los judíos piadosos del relato habrían evitado contaminarse con el uso y la mirada de la moneda prohibida, independientemente de su localización geográfica.

Por otra parte, no existe razón alguna para dudar que Jesús compartiera la actitud de sus correligionarios respecto a la idolatría y a las imágenes, y, por consiguiente, también en lo relativo a las monedas romanas. En consecuencia, resulta difícil conciliar su probable actitud religiosa con una narración que le describe mostrando o pidiendo que le mostraran un denario del emperador, fijando su mirada en la efigie prohibida.

Rist se cuestiona, entonces, cómo pudo introducirse el denario en la escena judía. ¿Tiene la función de adaptar una tradición recibida, proveniente de una situación judía, para responder a un problema que había surgido entre los cristianos gentiles? Si la adaptación hubiera sido solo con fines narrativos, se podría haber esperado una pregunta de Jesús como “¿de quién es esa moneda?”; en su lugar tenemos una cuestión más natural y directa: “¿de quién es esa imagen e inscripción?”. La referencia aparentemente innecesaria sobre la inscripción es especialmente significativa; pues es la inscripción, más que la imagen del emperador, la que explícitamente vincula la moneda al culto imperial. Por consiguiente, mediante el ingenioso recurso de introducir el denario en la narrativa, el énfasis de la perícopa se desplaza desde el problema judío de rendir tributo al emperador al dilema cristiano de rendir culto al emperador.

Un redactor cristiano de origen gentil, acostumbrado a estas monedas a lo largo de su vida y carente de la larga herencia de la ley judía que hacía de las imágenes tabúes, no encontraría ninguna irregularidad en la escena. La forma actual de la perícopa de Mc refleja, así, una situación de conflicto entre las exigencias religiosas del emperador y de Dios, ofreciendo una solución al dilema: los cristianos son súbditos leales del emperador (cf. Rom 13,1-7; 1 Ped 2,17) como se muestra mediante el pago de impuestos. Sin embargo, deben adorar a Dios, no al emperador, pues el culto pertenece solo a Dios. Vemos cómo una tradición recibida, que trataba el problema judío del pago de los impuestos al emperador, ha sido utilizada y adaptada para sancionar la actitud que los cristianos deben asumir frente al culto del césar. Cabe señalar que Justino, Ireneo y Tertuliano, entre los primeros padres, citan el incidente del evangelio como enseñanza de la actitud cristiana hacia el culto imperial. 
La interpretación de Rist es interesante al considerar el denario como una inclusión de Mc. No obstante, también tendría que haber tenido en consideración el añadido redaccional de los interlocutores ("los herodianos") para poder descubrir el contexto histórico del evangelista.

\subsection{Los herodianos como interlocutores de Jesús: ¿un añadido redac- cional?}

Los exegetas siempre se han sorprendido de esta extraña alianza de adversarios, la cual ya aparece al final del ciclo galileo de relatos de disputa (Mc 3,6), donde los fariseos celebran el consejo con los herodianos para ver cómo acabar con Jesús. En los dos relatos donde aparecen los herodianos (Mc 3,6; 12,13), estos surgen de improviso junto a los fariseos y de forma igualmente inopinada desaparecen de la narración. En ambos casos, los fariseos son mencionados en primer lugar.

No obstante, es poco realista el cuadro que nos presenta Marcos para el tiempo de Jesús, pues es difícil imaginar a los miembros de la élite herodiana que fueran enviados y se dejaran enviar por otras personas, incluso aunque fueran los líderes religiosos descritos en 11,27. Además, estos dos grupos mantenían visiones distintas respecto al tema controvertido del tributo. Los herodianos consideraban lícito pagar impuestos a Roma directamente, como sucedía en Judea en tiempos de Jesús, o indirectamente mediante los gobernantes vasallos herodianos (en Galilea y Gaulanitis). De forma diversa a los acomodaticios herodianos, los fariseos, o probablemente esos que se acercaron a Jesús, interpretarían el pago del tributo a Roma como idolatría, al menos esa fue la actitud de algunos fariseos tal y como se comprueba por la reacción del fariseo Saduco, quien en el año 6 d.C. se unió a Judas el Galileo en la revuelta contra Roma causada por intento imperial de imponer el tributo a Judea (Josefo, $B J$ II 118; $A J$ XVIII $1,1)$. No obstante, no es claro que los fariseos tuvieran una posición clara y unánime referente a esta cuestión. La mayoría de los fariseos en tiempos de Jesús probablemente consideraban el gobierno pagano como un mal inevitable, con que el que se podía cooperar pero no confraternizar (cf. $\mathrm{m}$. Abot 1,10; 2,3; 3,2; b. Pesah 112b; b.B. Qam. 113a). Unas décadas más tarde, un dirigente fariseo, Yohanan ben Zakkai, abogaba por la sumisión de los judíos a los romanos antes que la rebelión ${ }^{117}$. Tal vez, Marcos deseaba pre-

117 F.F. Bruce, "Render to Caesar" 250s. 
sentar a los fariseos de tendencia acomodaticia actuando en connivencia con los herodianos e intentando poner en una disyuntiva a Jesús frente a las autoridades romanas ${ }^{118}$.

Al margen de la actitud de los fariseos frente al tributo romano, el problema siempre ha sido determinar la identidad y la posible historicidad de la referencia a los herodianos y su relación con Jesús. Dado el tono político del relato, si consideramos tradicional la mención de los herodianos, éstos podían ser los sirvientes, cortesanos o funcionarios de Herodes Antipas, quien habría utilizado a sus aliados y sirvientes para acechar a Jesús y desacreditarlo en público. Según John Meier ${ }^{119}$, pudo acontecer que durante el ministerio público, algunos herodianos, en el sentido de partidarios ${ }^{120}$, funcionarios o sirvientes de Antipas hubieran discutido con Jesús o le tendieran trampas verbales. No podemos olvidar que Jesús provenía del territorio de Herodes Antipas, que predicaba la llegada del reino de Dios y se creía descendiente de David, lo cual tenía connotaciones políticas amenazadoras para los herodianos. Es probable, por tanto, que éstos desearan plantearle la cuestión política relevante sobre el pago de los impuestos, tema al que los herodianos eran particularmente sensibles, dado que la dinastía herodiana, como cliente de Roma, insistiría en la importancia del pago de los impuestos. En el año 66 d.C., Agripa II, un gobernante herodiano, intentó persuadir a sus compatriotas judíos para que pagaran los impuestos y así evitar la gran revuelta (BJ II 404). Sus intentos de persuasión, sin embargo, no fructificaron, lo que desembocó en la guerra ( $B J \mathrm{~V}$ 405-6). A pesar de esta plausible hipótesis ${ }^{121}$, sin embargo existe una incertidumbre sobre su identificación, ya que los escasos textos del NT que los

118 En contra de Evans, Mark 244, quien supone que Mc presenta a dos grupos con visiones opuestas sobre el pago de impuestos, una interpretación que resale a san Jerónimo.

119 John Meier, The Historical Jesus and the Historical Herodians, en: JBL 119 (2000) 740-746.

$120 \mathrm{El}$ análisis de las terminaciones, en latín -iani y en griego -ıavoí, o -€lol, dentro de la obra de Josefo y de la literatura clásica, ha mostrado su significado: partidario o partisano de alguna persona. Por tanto, el concepto ' $\mathrm{\rho} \omega \delta\llcorner\alpha \nu o i$ pudiera referirse a los miembros de la familia (sirvientes domésticos o esclavos), oficiales, soldados, sus cortesanos o funcionarios y, más generalmente, todos los partidarios del régimen de Herodes, pertenecieran o no a un grupo organizado. Rowley no considera probable que fueran los sirvientes domésticos ni los oficiales, sino hombres influyentes cuya actitud era amigable hacia la familia herodiana y, por tanto, hacia Roma, en la que se apoyaba. Puesto que Herodes, a imitación de César, se había convertido en el nombre de una dinastía, no es posible determinar a qué Herodes se alude en este caso. Cf. H.H. Rowley, The Herodians in the Gospels, en: JTS 41 (1940) 14-37; John Meier, "The Historical Jesus".

121 Joel Marcus, Mark 8-16 (The Anchor Yale Bible 27A), Yale University Press, New Haven - London 2009, 816. 
mencionan no dicen nada sobre su identidad, cuestión ésta que trataremos en otro artículo122.

Pero la clara combinación de intereses religiosos y políticos, así como la posición simétrica de esos dos relatos de disputa en el evangelio de Mc debe juzgarse más como arte teológico que como historia, tal y como John Meier afirma. Así, difícilmente puede ser histórica la presentación de los fariseos en 3,6, donde buscan matar a Jesús simplemente por haber dicho algo a un paralítico, sin haber realizado algo que hubiera quebrantado la legislación referente al sábado. Una vez descartada la historicidad de la conspiración mencionada en 3,6, la participación de los herodianos en tal conspiración queda también excluida. De esta forma, una de las dos apariciones de los herodianos en Mc deja de tener valor como dato histórico.

La cuestión que nos interesa dilucidar en este caso es si Mc 3,6 y 12,13 aportan alguna información histórica sobre incidentes específicos relativos a Jesús y los herodianos. La presencia de los herodianos como aliados de los fariseos precisamente en el versículo final de la curación en sábado y en el versículo introductorio de la perícopa sobre el tributo al emperador suscita demasiadas sospechas para poder servir de sólida base para argumentar a favor de la historicidad. John Meier, como la mayor parte de los estudiosos, atribuye estos versículos $(3,6$ y 12,13) a Marcos o a algún recopilador premarcano de relatos de disputa. Por consiguiente, se trataría de un producto redaccional. Estas perícopas circulaban como formas aisladas en la tradición oral sin referencia a posibles acontecimientos históricos subyacentes $^{123}$. Mc 12,13 se entiende mejor como un caso similar de creación redaccional efectuada por Mc a favor de la simetría al situar sus dos ciclos de los relatos de disputa en Galilea y Jerusalén. Por eso Mc 3,6 y 12,13 no nos dicen nada fiable sobre incidentes de la vida de Jesús ${ }^{124}$. En un sentido amplio, la vinculación de los fariseos y los herodianos delimita el ministerio público, presagiando desde el principio en Galilea la oposición mortal de las fuerzas políticas y religiosas que finalmente daría su fruto en Jerusalén.

122 David Álvarez Cineira, Los Herodianos y el fiscus Iudaicus en Mc 12,13-17, en: EstAg.

123 Para C.S. Mann, Mark (The Anchor Bible), Doubleday, New York - London 1986, 468, no hay dudas de que se trata de un auténtico incidente histórico, pues la respuesta de Jesús tiene todo el carácter enigmático que caracterizó muchos de los dichos de Jesús, incluso se podría ubicar en la última semana de Jesús ya que Lc 23,7 menciona que Herodes Antipas se encontraba en Jerusalén para celebrar la pascua.

124 John Meier, Un judio marginal III 576s. 
El carácter redaccional de Mc 12,13 y no un recuerdo histórico viene corroborado por el mismo hecho de que los fariseos y herodianos no aparecen implicados para nada en el juicio y la condenación a muerte de Jesús.

\section{Conclusión}

La anexión de Judea al imperio romano supuso el pago del impuesto de capitación, el cual era recaudado muy probablemente por la administración religiosa judía, para hacerlo llegar al prefecto. Su exacción, sin embargo, no estaba estipulado que fuera en metálico y, menos, en denarios romanos, por lo que la población judía podía hacer efectivo su contribución con monedas de bronce, monedas de Tiro o con grano. Además, los estudios numismáticos han corroborado que la monetización romana, y especialmente la circulación de monedas de oro y plata (denarios), era escasa en Judea antes de la destrucción del Templo de Jerusalén, lo cual haría inviable que los sujetos del impuesto de capitación tuvieran que abonarlo en denarios imperiales. Por consiguiente, la mención del denario, además de los interlocutores (los herodianos) en el relato de Mc se debe a la labor redaccional del evangelista. La inclusión de estos rasgos redaccionales se debe al conflicto de la comunidad de Mc, probablemente en Roma, que tras la destrucción del templo de Jerusalén tiene que abonar en la capital del imperio el fiscus Iudaicus mediante la moneda común en esa ciudad. Ante esta imposición del emperador Vespasiano, la comunidad cristiana se cuestiona: “¿pagamos o no pagamos?" (v. 14). El redactor de Mc responde a la cuestión mediante un logion de Jesús que había proferido en otro contexto tras haber sido cuestionado por los fariseos: "Lo del César pagádselo al César, y lo de Dios a Dios" (v. 17). 